\title{
REVIEW
}

\section{Do Corticosteroids Still Have a Role in the Management of Third Molar Surgery?}

Wei Cheong Ngeow · Daniel Lim

Received: April 19, 2016/ Published online: June 10, 2016

(C) The Author(s) 2016. This article is published with open access at Springerlink.com

\section{ABSTRACT}

Introduction: The use of corticosteroids to reduce the post-operative sequelae of lower third molar surgery, namely pain, swelling and trismus, has been well studied by many researchers over the past 6 decades. This study reviewed the reported outcome of corticosteroids used in controlling the above sequalae after third molar surgery.

Materials and Methods: A PubMed, Medline, EMBASE and Google search was undertaken of all controlled clinical trials on the effects of corticosteroids on pain, swelling and trismus after lower third molar surgery. The review was limited to studies published over the last 10 years (2006-2015).

Enhanced content To view enhanced content for this article go to http://www.medengine.com/Redeem/D7D 4F06054432A56.

W. C. Ngeow $(\bowtie) \cdot$ D. Lim

Department of Oro-Maxillofacial Surgical and Medical Sciences, Faculty of Dentistry, University of

Malaya, 50603 Kuala Lumpur, Malaysia

e-mail: ngeowy@um.edu.my

W. C. Ngeow

Department of Oral and Maxillofacial Surgery,

School of Dentistry, University of California,

San Francisco, 533 Parnassus Avenue, UB08,

San Francisco, CA 94143-0440, USA
Results: Of the 46 initially retrieved articles, 34 were finally included. Eleven studies compared the effect of 2 similar (but different dose) or different group of corticosteroids. Thirty-one studies reported the effects of corticosteroids on all sequale, 2 reported the outcome on swelling and trismus and another 1 on swelling and pain only. In 16 of the studies, corticosteroid use resulted in significant reductions in pain after third molar removal. Twenty-two out of 29 studies reported reduced swelling against negative control while 18 out of 25 studies reported improved mouth opening. Fourteen studies reported the benefit of corticosteroids on all 3 sequelae, with $71.4 \%$ resulted from the use of methylprednisolone.

Conclusion: Although there are some conflicting effects, the results of this analysis shows in general the benefits derived from short-term use of corticosteroids in relation to pain, swelling and trismus following third molar surgical extraction, with no side effects observed.

Funding: This work was supported by the University of Malaya's High Impact Research grant UM.C/625/1/HIR/MOHE/05. 
Keywords: Corticosteroids; Pain; Surgery; Swelling; Third molar; Trismus

\section{INTRODUCTION}

Surgical removal of impacted lower third molars is one of the most commonly performed surgical procedures in any dental surgery worldwide. Although it is a minor surgical procedure, the common sequelae, which are pain, swelling and trismus, can severely affect patients' quality of life during the immediate post-operative period [1]. These sequelae arise as a result of tissue inflammatory process, with cardinal signs of inflammation that include pain (dolor), heat (calor), redness (rubor), swelling (tumor) and loss of function (function laesa) [2]. There are considerable variations from patient to patient in the occurrence and severity of the inflammatory symptoms.

In the past, many different approaches, including drains, laser therapy and medications with enzymes, muscle relaxants or corticosteroids were clinically evaluated in an effort to minimize these post-operative sequelae [3-6]. The last agent, namely the corticosteroids, have shown promising results. Corticosteroids are available as two main groups, the glucocorticoids and the mineralcorticoids. It is the glucocorticoids that are of interest here, because of their anti-inflammatory activities with little or no effect on fluid and electrolyte balance. The term corticosteroids will subsequently be used in this study to denote the former group of agents.

Corticosteroids are a class of chemicals that includes natural steroid hormones that are produced in the adrenal cortex of vertebrates as well as the synthetic analogues of these hormones. They are 21 carbon compounds having a cyclopentanoperhydro-phenanthene (steroid) nucleus and were first purified by Dr. William C. Kendall, who later on, together with Drs. Phillip S. Hench and Tadeus Reichstein, won a Nobel Prize for Physiology or Medicine. In 1948, Hench et al. successfully used cortisone and adrenocorticotropic (corticotropine) hormone to reduce the inflammatory process of rheumatoid arthritis [7]. Following this success, various other forms of corticosteroids have been synthesized as scientists found that the biologic properties of corticosteroids can be altered quantitatively and selectively by the substitution of certain chemical groupings and by minor configurational changes in molecular structure [3].

Dehydrogenation at the 1 position of the steroid nucleus gave rise to prednisone and prednisolone. This increased anti-inflammatory activity four to five times. During 1957, Arth et al. synthesized dexamethasone (9-alpha-fluoro, 16-alpha-methylprednisolone) which is a synthetic analogue of methylprednisolone in which a methyl group has been added at the carbon 16 position and a fluorine atom at the carbon 9 position $[8,9]$. The addition of fluorine at the carbon 9 position greatly enhances the anti-inflammatory activity of the new compound. Dexamethasone has a milligram activity 5-10 times of predisone and prednisolone, and 30 times that of cortisone [10].

Corticosteroids are classified according to their duration of action. Short-acting glucocorticoids include cortisol (hydrocortisone) and cortisone, with duration of action less than $12 \mathrm{~h}$ and anti-inflammatory potency of 1 . Intermediate acting glucocorticoids have duration of action of $12-36 \mathrm{~h}$. They include prednisone and prednisolone with anti-inflammatory potency of 4, and 6-methylprednisolone and 
triamcinolone, both having anti-inflammatory potency of 5. Dexamethasone and betamethasone are long-acting glucocorticoids, with duration of action greater than $36 \mathrm{~h}$ and anti-inflammatory potency of 25 (Table 1) [11].

As seen in Table 1, to obtain a similar effect of $10 \mathrm{mg}$ prednisolone, one needs to prescribe $8 \mathrm{mg}$ methylprednisolone, $50 \mathrm{mg}$ cortisone, $40 \mathrm{mg}$ hydrocortisone (cortisol), or $1.5 \mathrm{mg}$ betamethasone or dexamethasone. These doses are twice the equivalent to the physiological output of cortisol by the adrenal cortex in an average individual during an average day [12].

Corticosteroids reduce inflammation via the inhibition of phospholipase A2, which is the first enzyme involved in the conversion of phospholipids into arachidonic acid, therefore blocking the synthesis of other products such as prostaglandins, leukotrienes and substances related to thromboxane A2 [13]. In essence, corticosteroids stop the formation of these end products which is a broth of potent inflammatory mediators that causes the signs and symptoms described above [2]. They also have the ability to stabilize lysozyme membranes, decrease the release of inflammation-causing lysozymes, and decrease the permeability of capillary which thus prevents diapedesis, i.e. the initial leakage of fluids from the capillaries and loss of plasma protein into tissue space $[3,11]$. There is also a decrease in the formation of bradykinin, a powerful vasodilating substance [3].

Strean is credited with publishing a paper which represented the first scientific approach to the general use of corticosteroids in dentistry [14]. Both Strean (together with colleague, Horton) and Spies et al. were the first to use (hydro)cortisone for the treatment of oral diseases related to local causes and oral manifestations of inflammatory systemic disease [15, 16]. However, it was an editorial by Kenny that first suggested the use of steroids for managing post-operative sequalae [17]. Following that, Ross and White confirmed this anti-inflammatory effect by using oral hydrocortisone against placebo in a double blind study involving third molar surgeries [18]. Since then, the use of corticosteroids for third molar surgery had been studied extensively in different formulations, dosings, routes and sites of administration. These corticosteroids include dexamethasone (per oral/p.o.), dexamethasone acetate

Table 1 The duration of action and anti-inflammatory potency of glucocorticoids

\begin{tabular}{lcll}
\hline Glucocorticoids & Anti-inflammatory potency & Duration of action & Equivalent dose \\
\hline Cortisol & 1 & Short $(<12 \mathrm{~h})$ & 20 \\
Cortisone & 0.8 & & 25 \\
Prednisone & 4 & & 5 \\
Prednisolone & 4 & Intermediate $(12-36 \mathrm{~h})$ & 5 \\
6-Methyl prednisolone & 5 & & 4 \\
Triamcinolone & 5 & & 4 \\
Dexamethasone & 25 & Long $(>36 \mathrm{~h})$ & 0.75 \\
Betamethasone & 25 & & 0.75 \\
\hline
\end{tabular}


(intramuscular), dexamethasone sodium phosphate (intravenous and intramuscular), methylprednisolone (p.o.), and methylprednisolone acetate and methylprednisolone sodium succinate (both intravenous and intramuscular) [19]. An attempt at undertaking a systematic review on the use of corticosteroids up to September 2011 by Herrera-Briones et al. turned into a narrative review due to the heterogeneity of many study designs, outcome measures, and routes of drug administration [20, 21]. Hence, this study does not attempt to replicate their work, but instead tries to answer some questions that arose from the systematic analysis. Quite a number of new reports have been published over the last 5 years, and we believe that some of them are able to address questions relating to the magnitude of the decrease in the clinical symptoms on the patients' quality of life, the timing of drug administration, the efficacy of administrating into the masseter muscle as compared other sites of intramuscular administration, and the effect of enteral intake versus parenteral routes. This article aims to review only studies that were carried out in the past decade in an attempt to determine any consistent effects of corticosteroids on swelling, pain and trismus with the objective of answering the following questions:

1. The effect of corticosteroids on patients' quality of life.

2. The timing of drug administration.

3. The efficacy of administrating into the masseter muscle as compared other sites of intramuscular administration.

4. The effect of enteral intake versus parenteral routes.

5. The adverse effect of corticosteroids administration, namely acute alveolar osteitis, post-operative infection and nausea.

\section{METHODS}

We performed this review in the spirit of summarizing important facts and findings from various relevant studies and literature to provide a state of the art update on the use of corticosteroids in third molar surgery. The methodology used in this study is an adaptation from the protocol used by Ata-Ali et al. [13]. A Pubmed, Medline, EMBASE and Google search was undertaken of all controlled clinical trials on the effects of corticosteroids on pain, swelling and trismus after lower third molar surgery. The review was limited to studies published over the last 10 years (2006-2015). This review included only articles that compared the use of corticosteroids in any formulation, dose and route/site with another corticosteroid or negative/placebo control group. Articles were excluded if they contributed unclear data on the patient selection, treatment, route of administration, dose and surgical procedure, measurement of sequalae or inadequate data on outcomes. Articles that compared corticosteroids with other drugs, intervention or treatment were excluded, except when the corticosteroid was administered with an adjuvant therapy related to third molar surgery, namely an antibiotic. A total of 34 articles were finally included (Tables 2, 3, 4), with documentation of the following from each of them: year of publication, number of patients in the study and control groups, corticosteroids administered, dosage, route and timing of administration, analgesic efficacy, anti-swelling effect, and effect on trismus.

\section{Compliance with Ethics Guidelines}

This article is based on previously conducted studies and does not involve any new studies of 


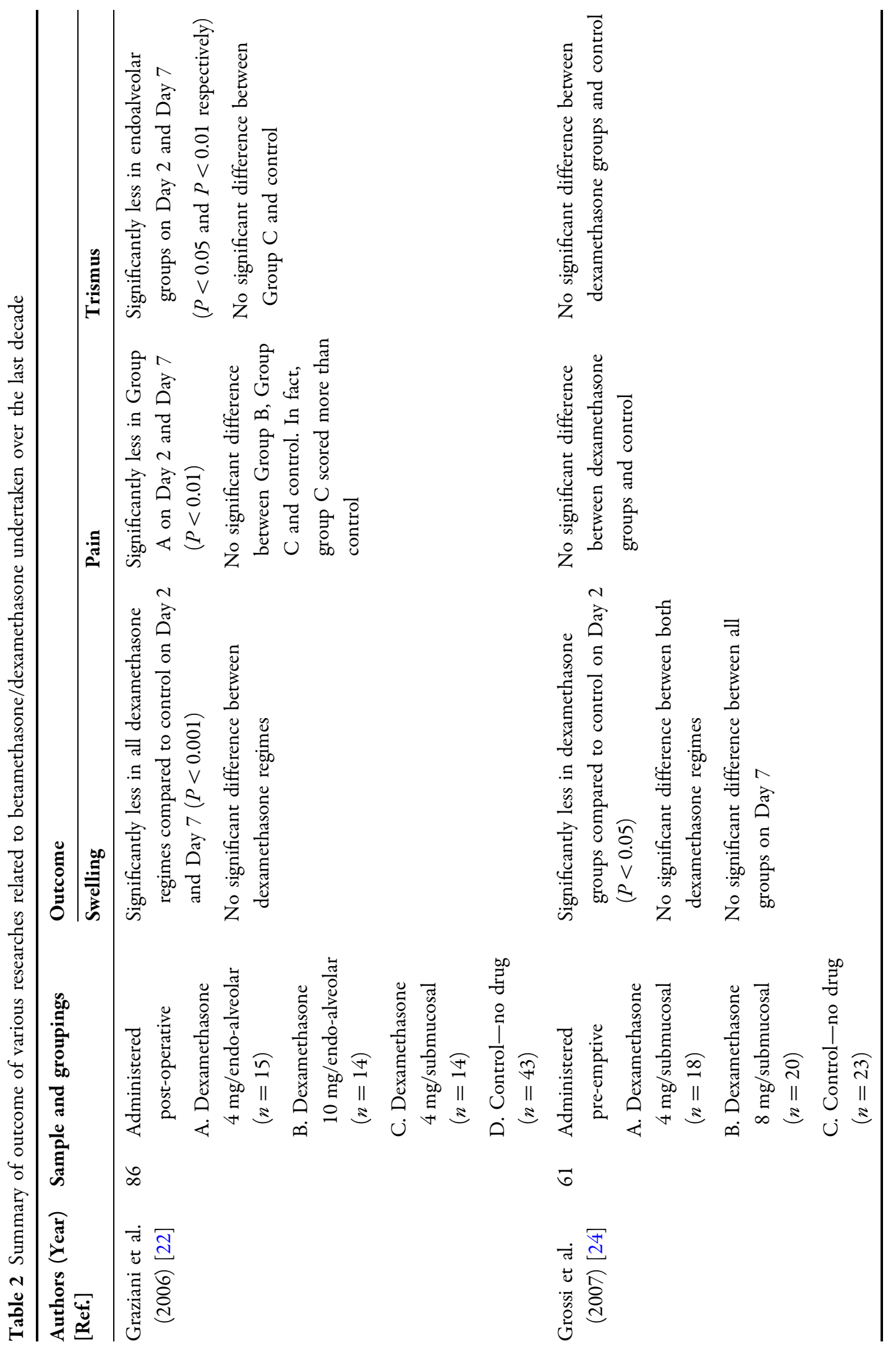




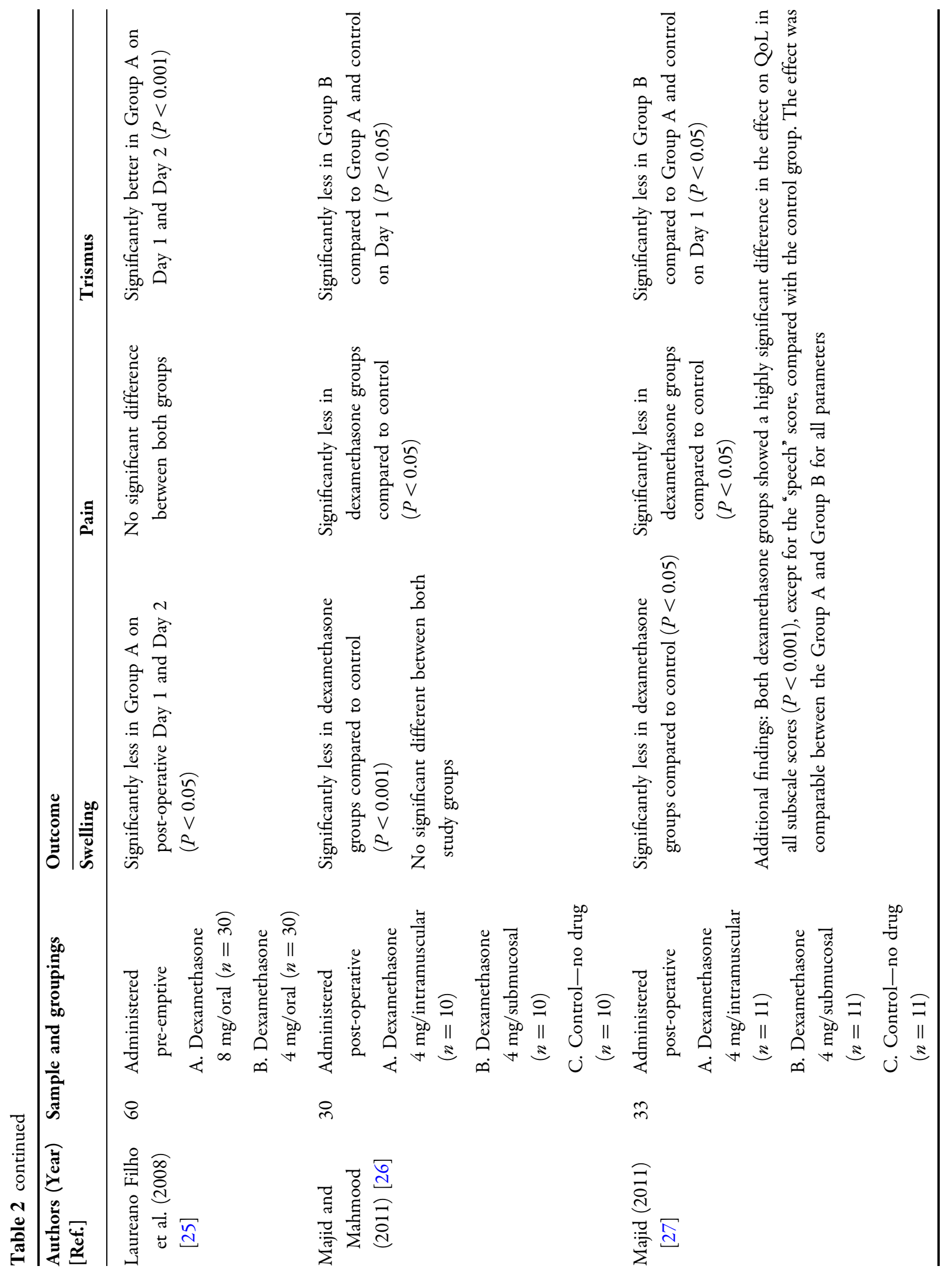




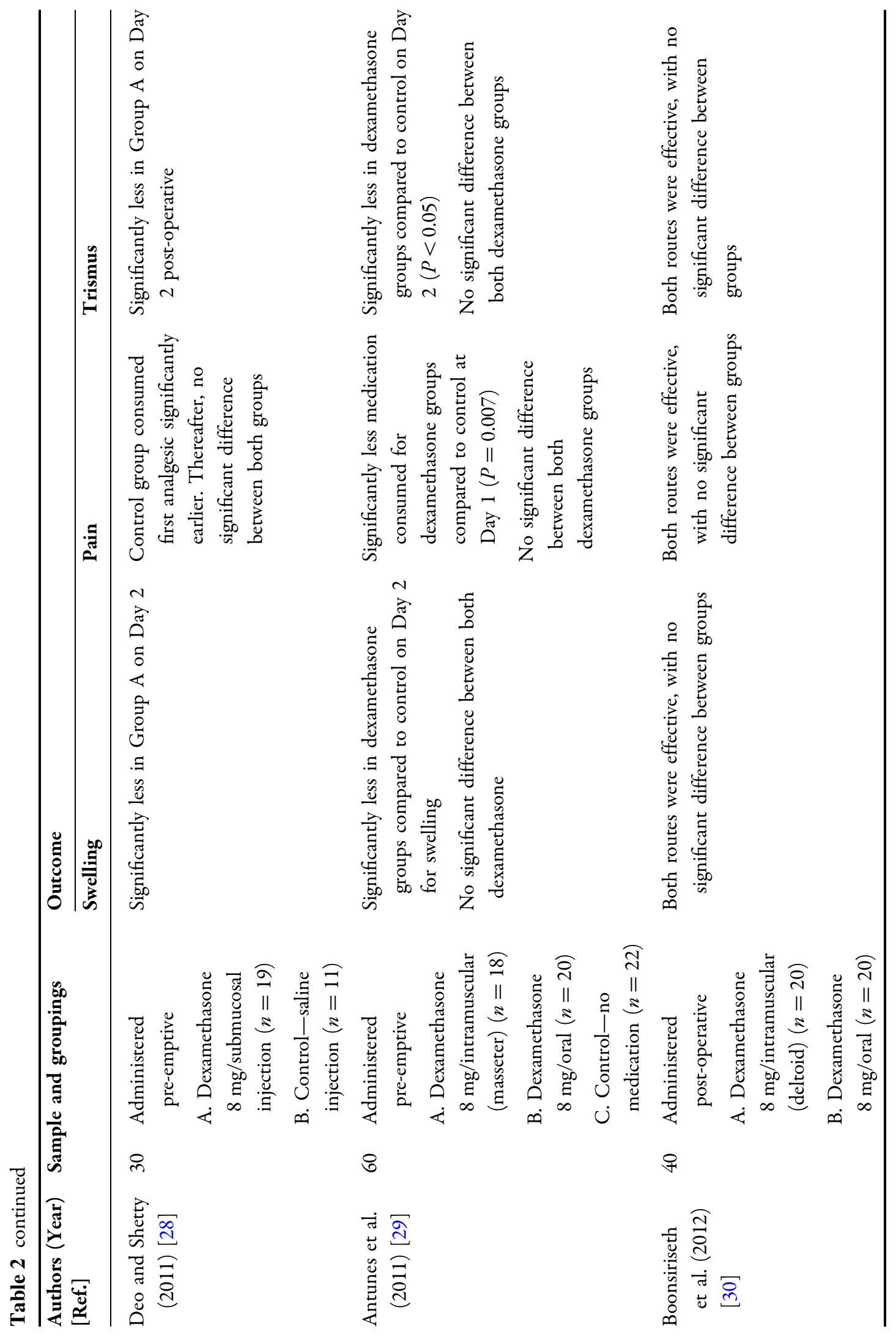




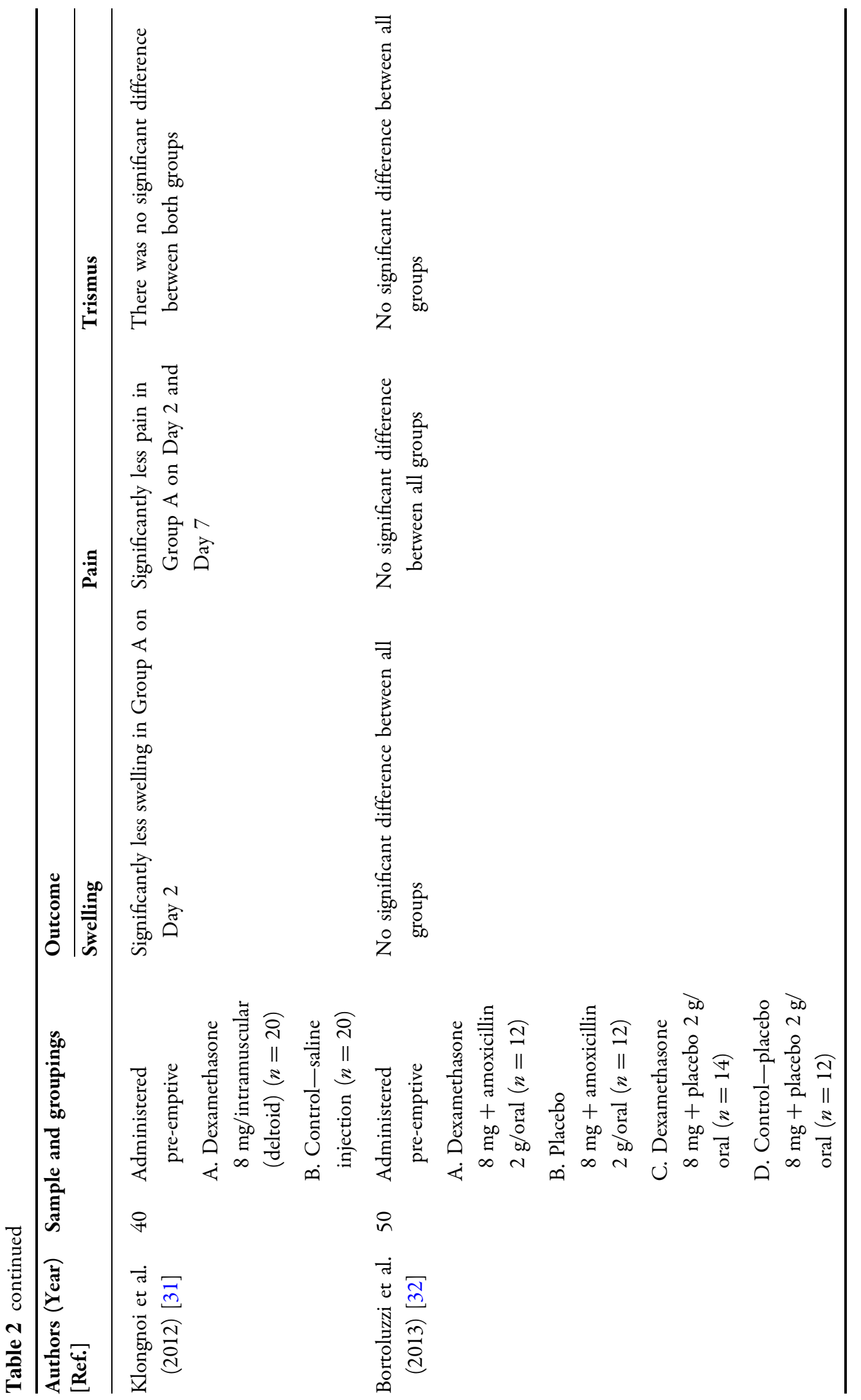




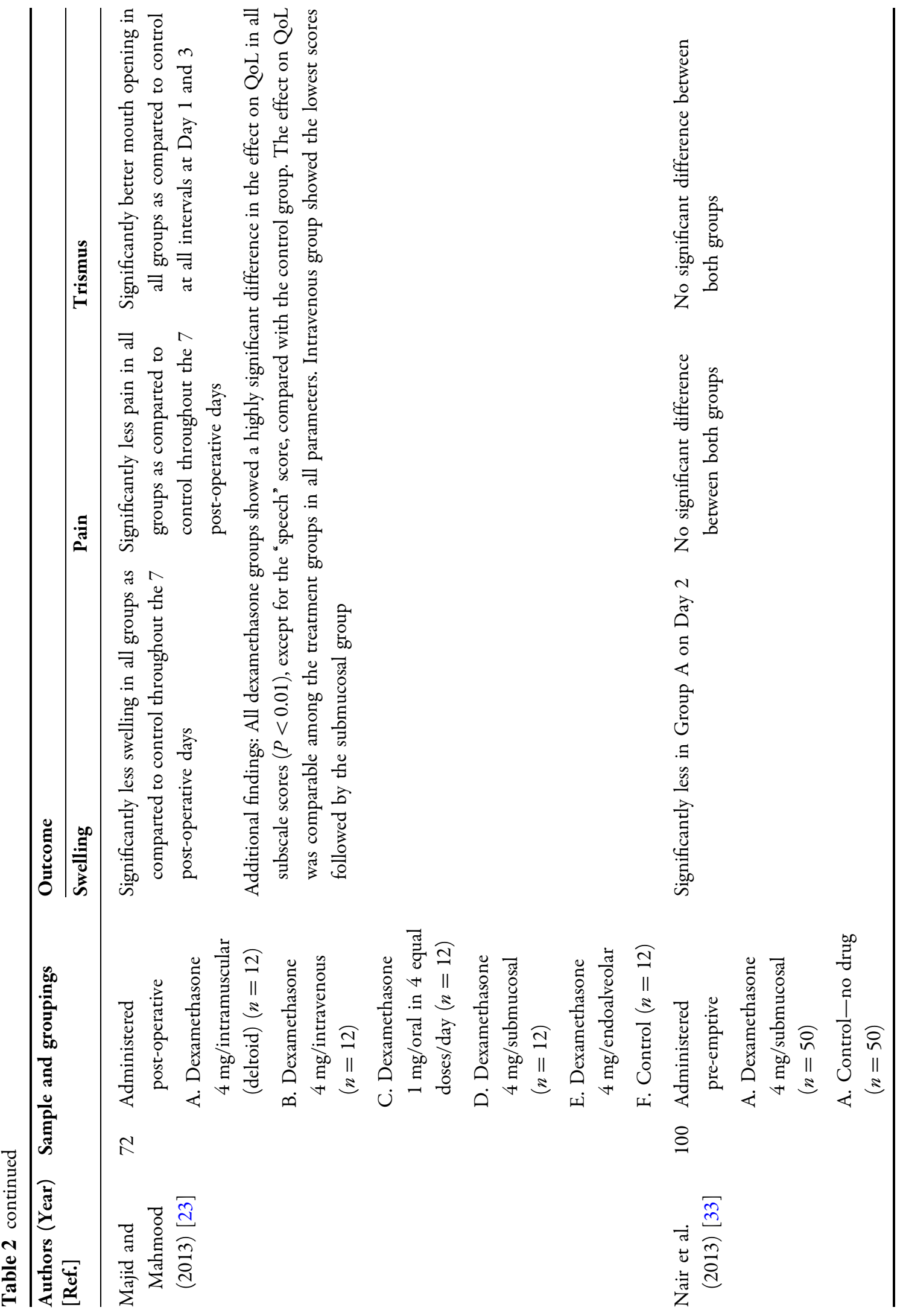




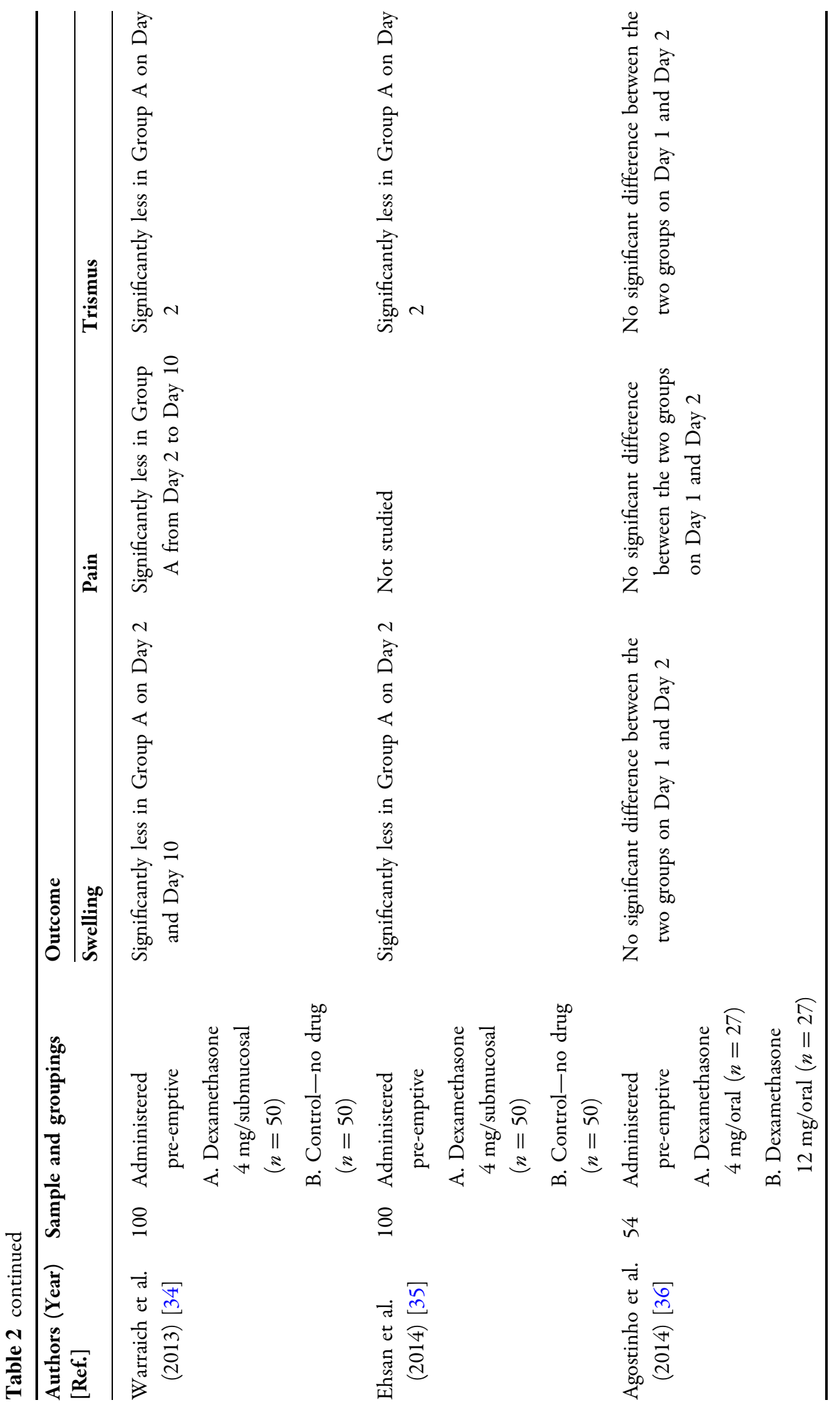




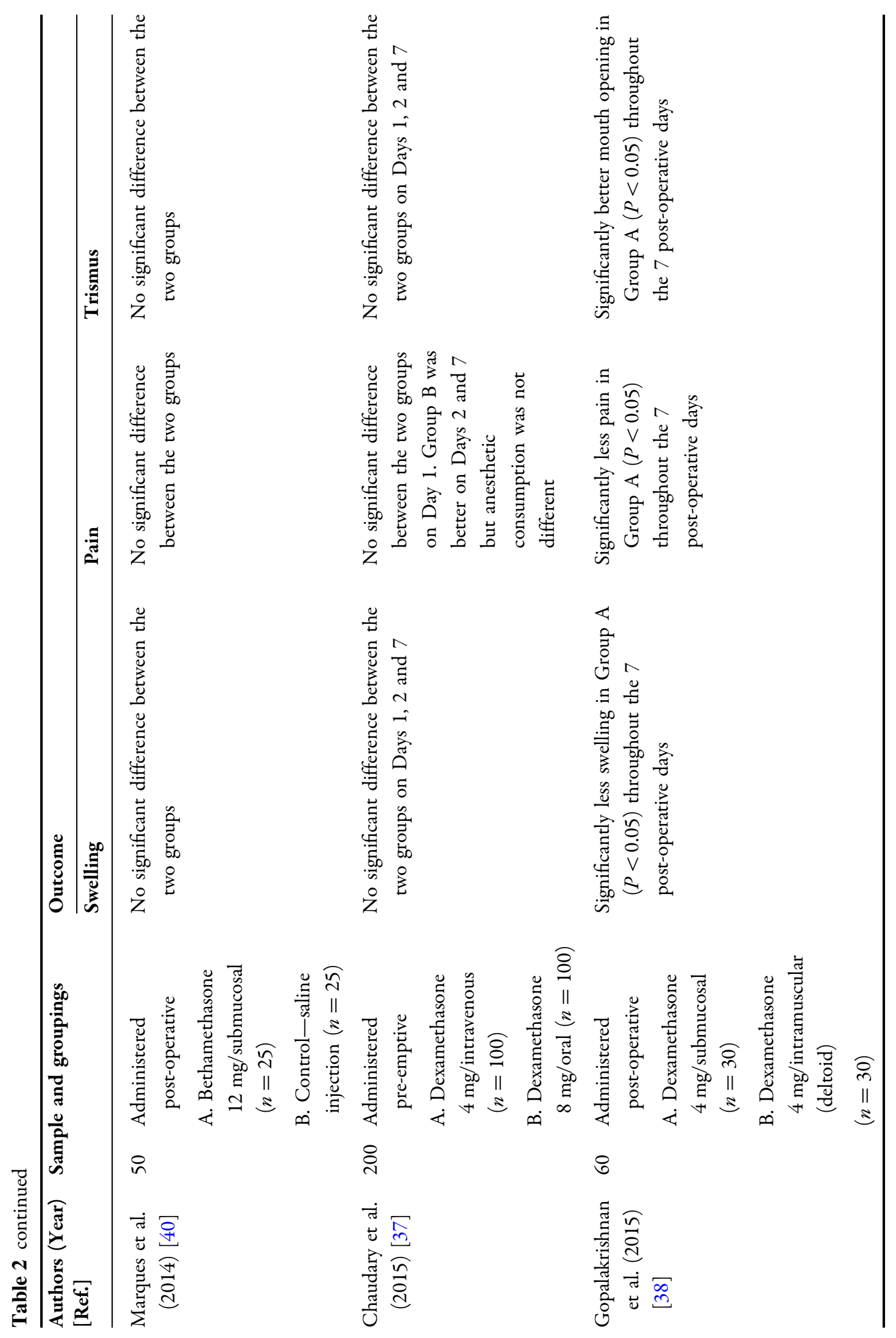




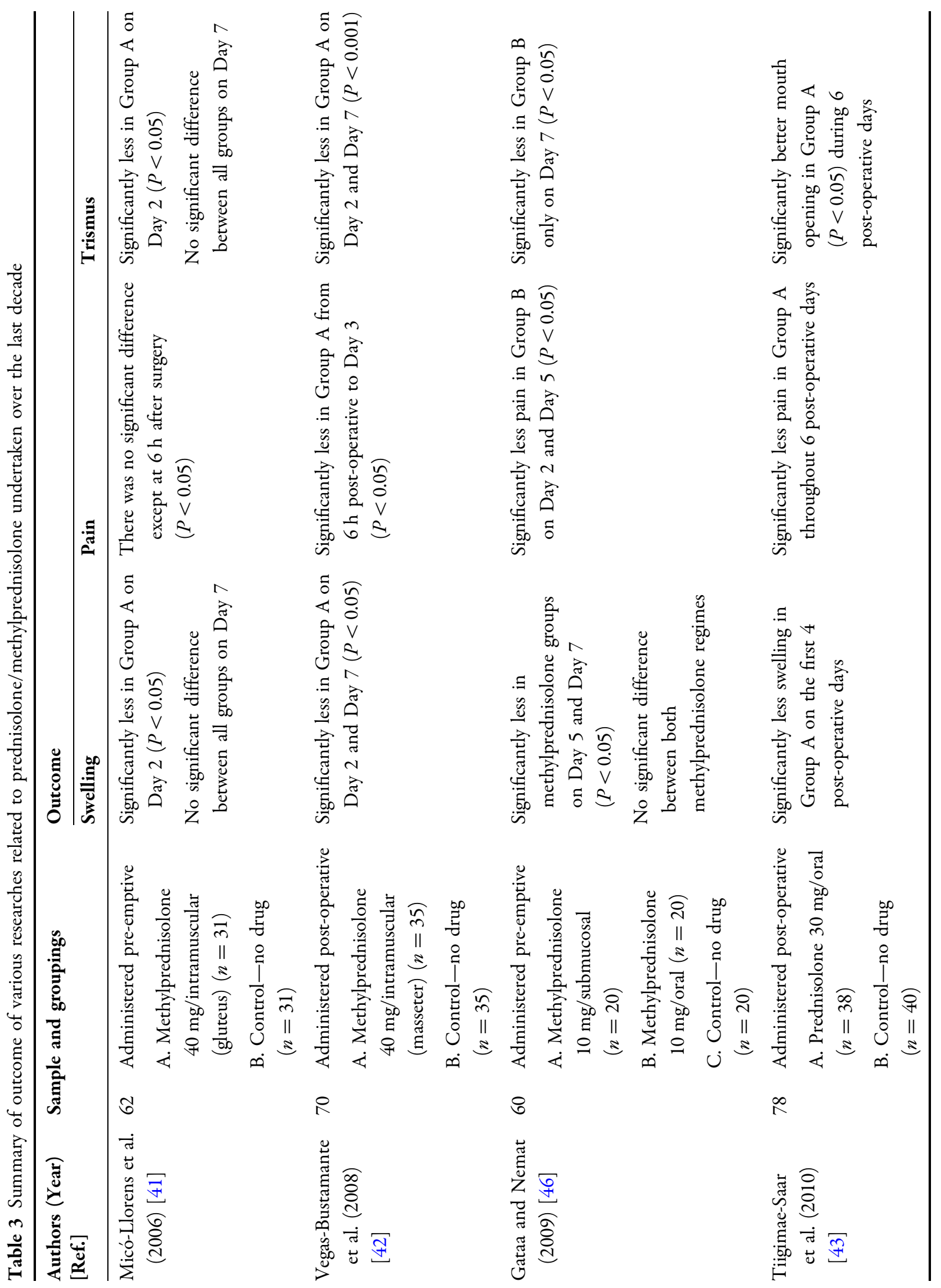




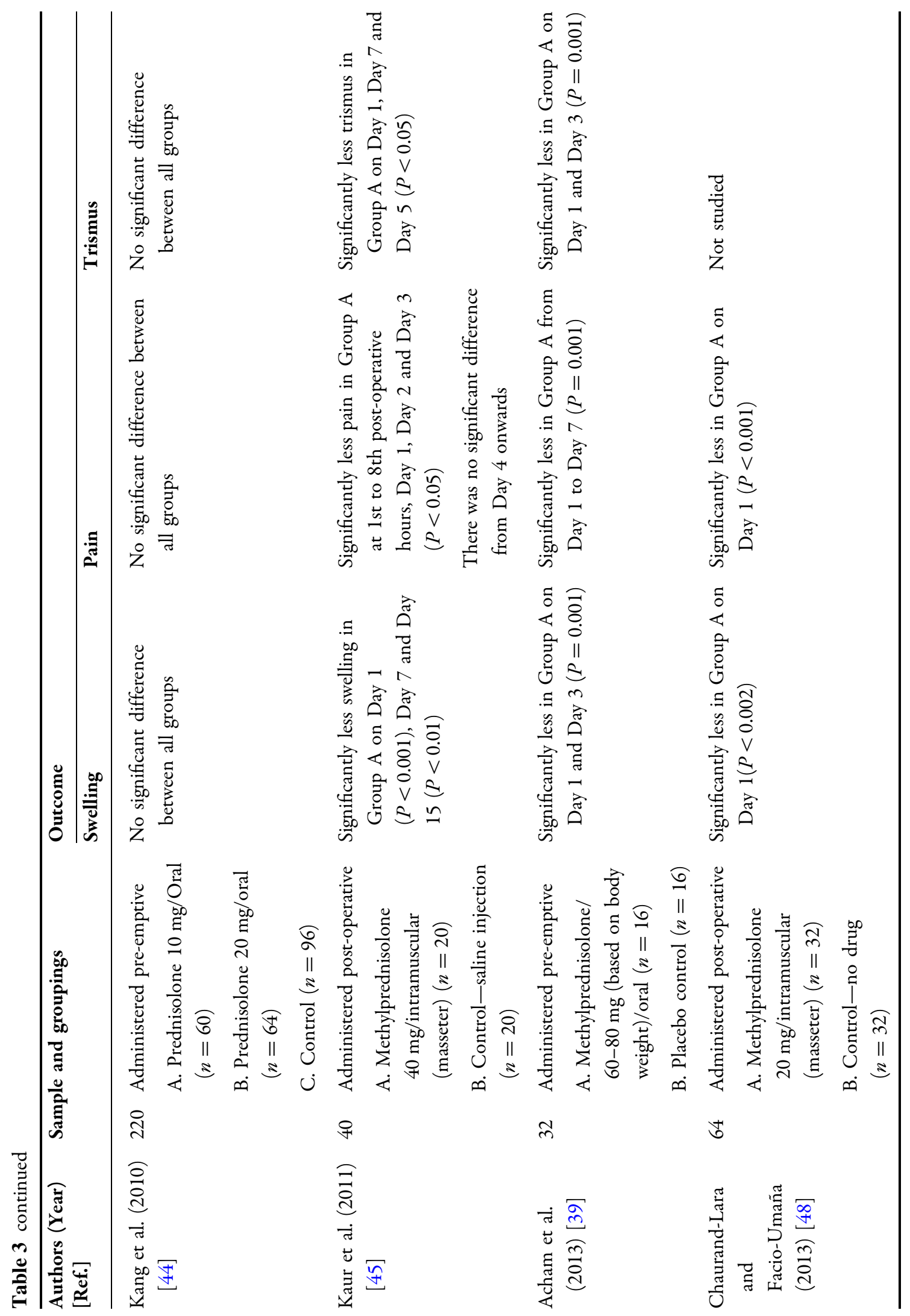




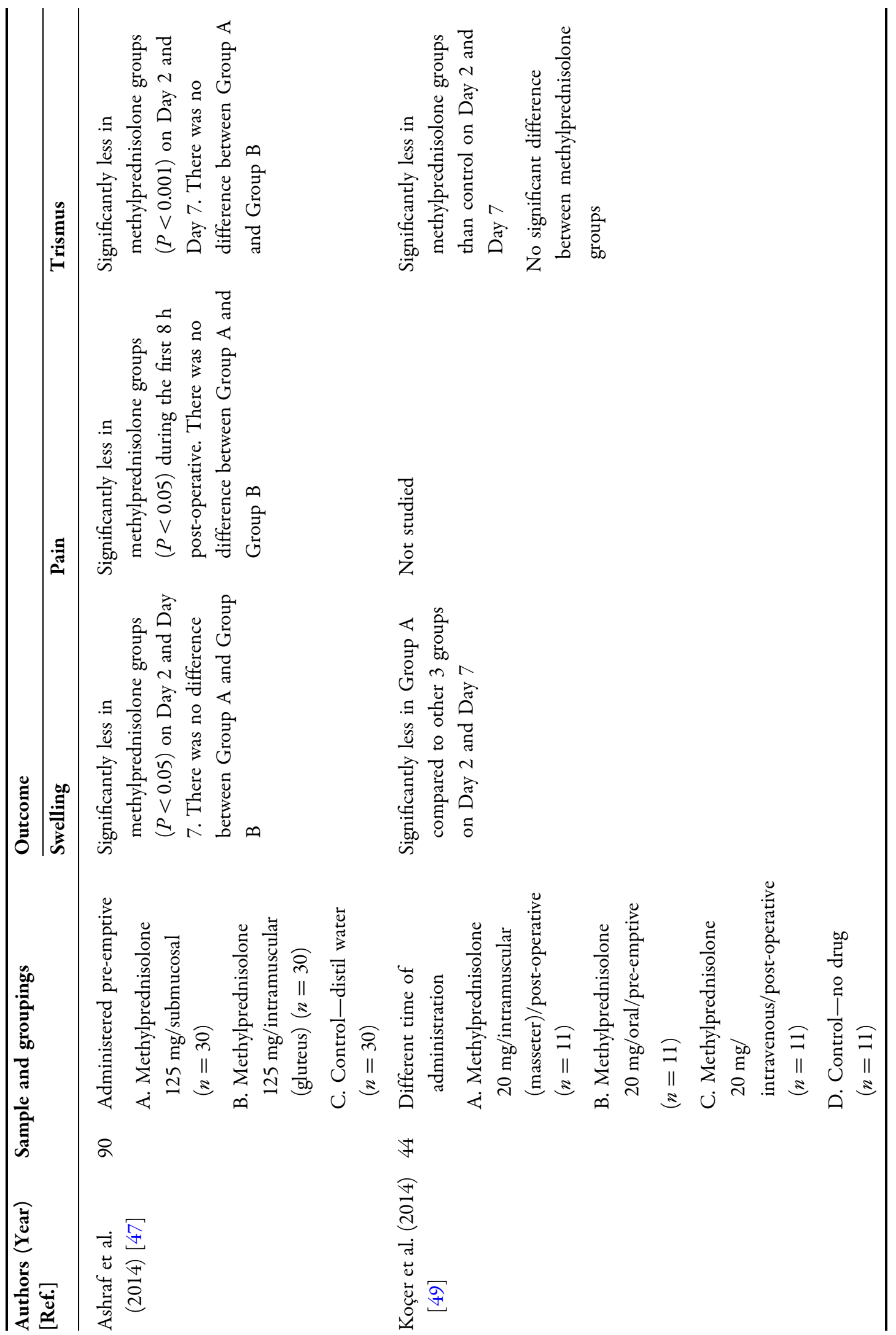




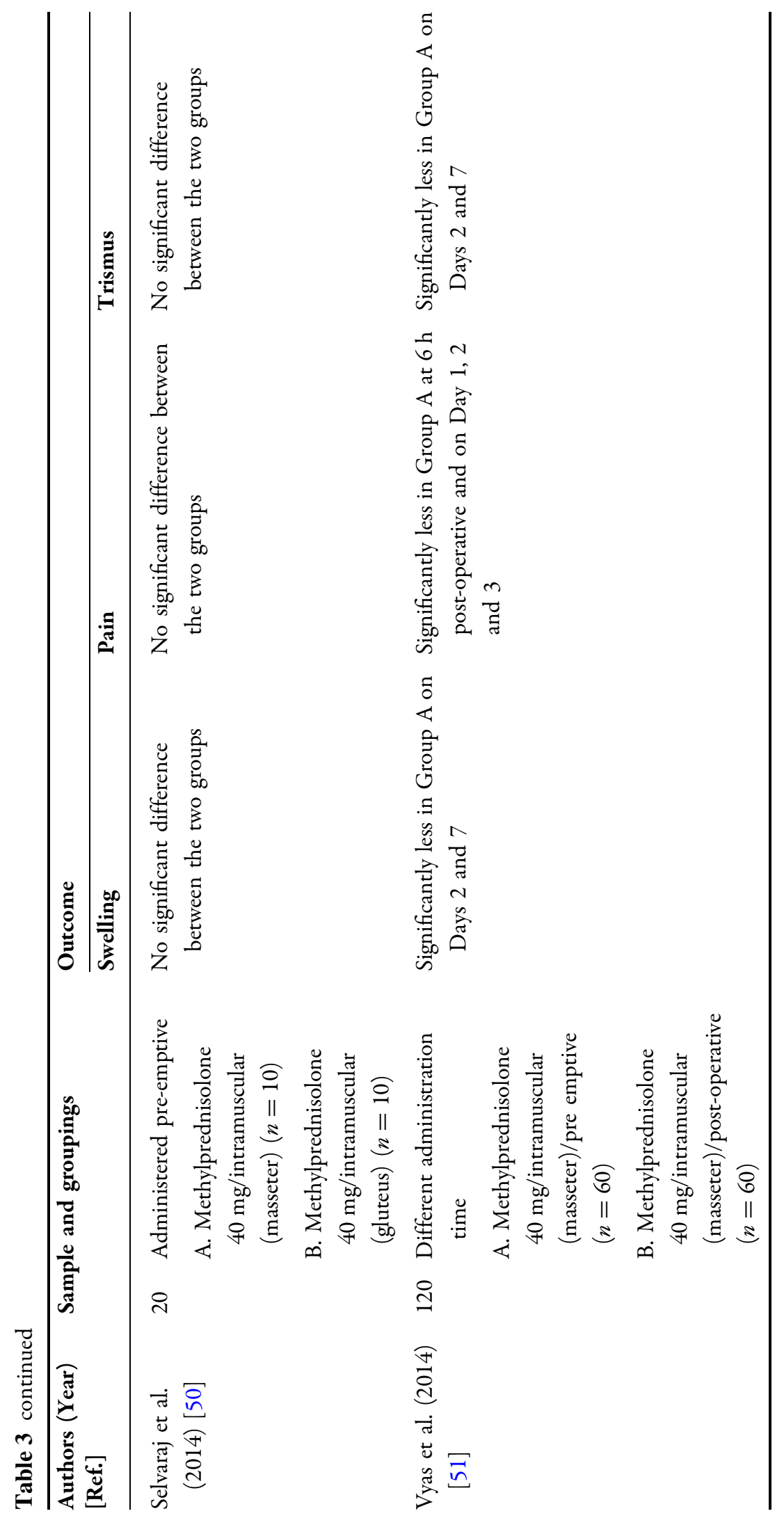




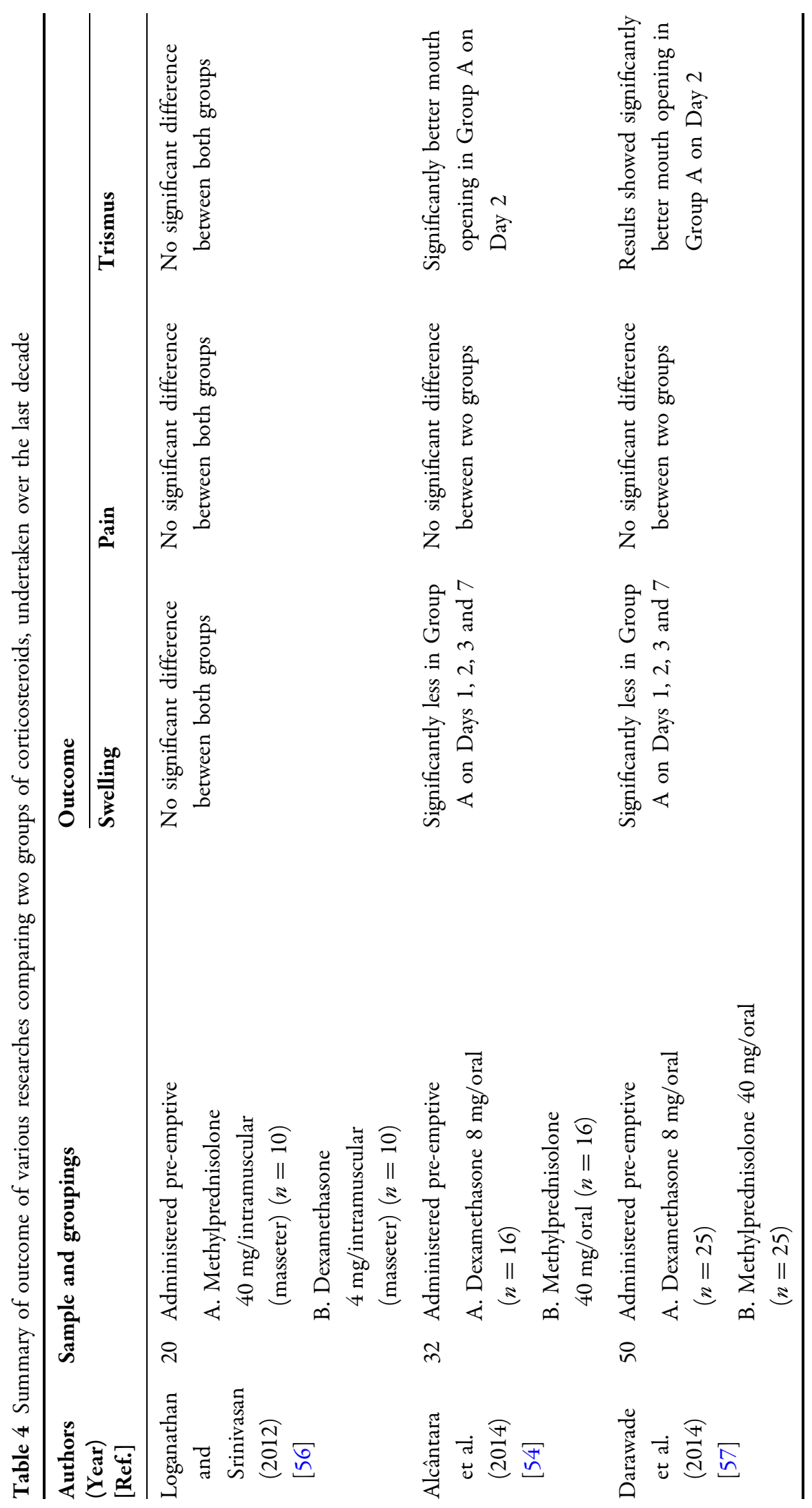




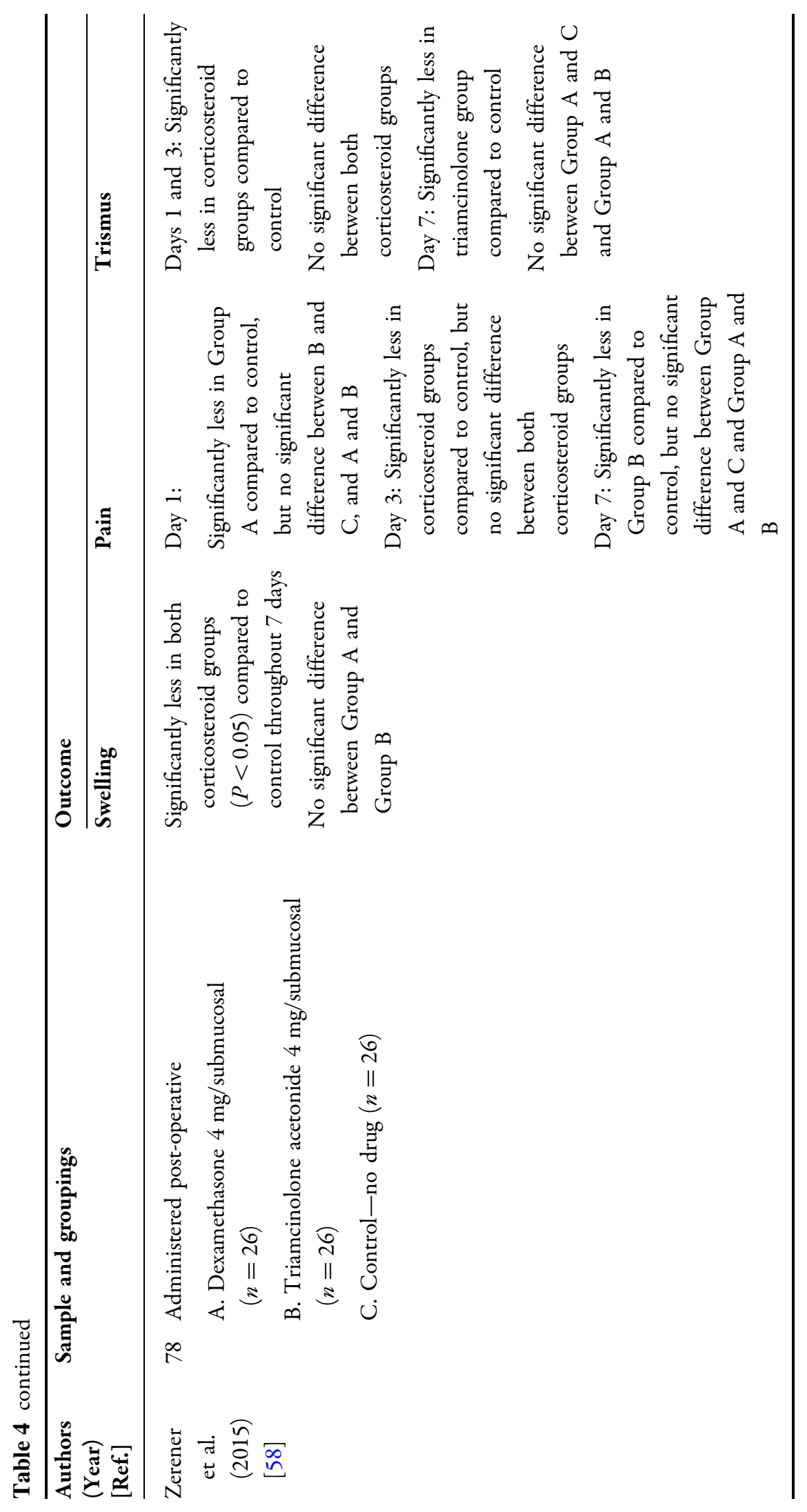


human or animal subjects performed by any of the authors.

\section{RESULTS}

During the past 10 years, the commonly studied corticosteroids for use in third molar surgery were dexamethasone (17 reports), methylprednisolone (10 reports), prednisolone ( 2 reports) and betamethasone (1 report). Four other studies compared two different steroids. Corticosteroids had been administered via various routes that included intravenous, intramuscular (masseter, deltoid or gluteus), submucosal, endo-alveolar and oral.

\section{Results Involving Dexamethasone}

Dexamethasone was first tested to control edema and to decrease trismus and pain after oral surgical procedures in 1965 [10], and since then, there has been a surge in popularity for its use in oral surgical procedures. It is one of the most frequently studied and used corticosteroids in oral and maxillofacial surgery [22-38] (Table 2). In early studies, it was usually given intramuscularly, and Messer and Keller [3] were of the opinion that the masseter muscle made a good site to receive injections because of its proximity to the third molar surgical site.

Fast forward to this millennium, newer methods of delivery have been adopted. Graziani et al. in 2006 compared the efficacy of dexamethasone given as submucosal injection and endo-alveolar application [22]. This study showed a significant reduction in swelling following the administration of submucosal dexamethasone and the placement of endo-alveolar dexamethasone post-surgically. It was reported that endo-alveolar application of $4 \mathrm{mg}$ dexamethasone significantly reduced trismus but this was not the case with submucosal injection. In addition, the low-dose dexamethasone powder applied endo-alveolarly reduced post-operative pain significantly when compared to others. This study introduced the endo-alveolar approach for administrating corticosteroid which has the benefit of easy placement, and providing a localized effect with reduced systemic side effects of corticosteroids. A further study on endo-alveolar application was later performed once and this study confirmed its benefit [23].

The following year, Grossi et al. compared the efficacy of increasing the dosage of dexamethasone to $8 \mathrm{mg}$, as compared to the $4 \mathrm{mg}$ used by Graziani et al. [22, 24]. Submucosal injection was given at the buccal tissue adjacent to the surgical site and was usually given after local anesthesia of the area had been achieved. This technique was easy and safe to perform, comfortable to patients and produce a localized more than a systemic one [22]. Grossi et al. found no significant difference between the dexamethasone and the control groups in reducing post-operative pain and trismus, although submucosal dexamethasone resulted in significantly less facial swelling on the second day post-operative [24]. The latter finding was supported by a post-operative symptom severity (PoSSe) scale with the control group reporting more changes in appearance than the study group. They concluded that $8 \mathrm{mg}$ dexamethasone was not superior to $4 \mathrm{mg}$ dexamethasone and recommended the use of the lower dose of dexamethasone to reduce post-surgical sequelae following third molar surgery. This recommendation concurs with that suggested by Graziani et al. [22]. 
Using the enteral approach, Laureano Filho et al. in 2008 compared the efficacy of different doses of dexamethasone given $1 \mathrm{~h}$ pre-operatively [25]. They found a significant reduction of post-operative sequelae with the use of a higher dose, i.e. $8 \mathrm{mg}$ of dexamethasone. The finding from this study differed from that reported by 2 previous authors who reported no significant benefit of giving a high dose of dexamethasone [22, 24]. As the corticosteroid was given via an enteral route, it has to undergo absorption in the gastrointestinal tract. So a higher dosage will definitely provide a higher load factor following absorption. This finding is in contrast to an early study half a century ago when Linenburg reported that an even lower dose $3 \mathrm{mg}$ of oral dexamethasone, taken as 3 divided doses over 2 days, with the first dose taken $1 / 2 \mathrm{~h}$ pre-surgery, was effective in reducing swelling and trismus [10]. Do note, however, that Laureano Filho et al. gave only one single dose, as compared to Linenberg's sustained prescription over 2 days. Despite the significant findings of Laureano Filho et al.'s work, a conclusion as whether oral $4 \mathrm{mg}$ dexamethasone was significantly effective could not be made since there was no negative control in this study [25].

Majid presented 2 reports on the effects of dexamethasone in 2011. In one of the reports, which was co-authored with Mahmood, he compared the effect of submucosal and intramuscular injection of $4 \mathrm{mg}$ dexamethasone after third molar surgery in 30 subjects [26]. Both routes produced significantly less swelling and pain than control. Submucosal dexamethasone was also reported to significantly reduce trismus on the first post-operative day. They suggested that submucosal injection had the advantage of reducing trismus because of its localized effect.
Since both routes of administration provided the same results with regards to swelling and pain, they were of the opinion that the submucosal route might perhaps be a better choice due to its ease of administration and the localized effect at the surgical site. The small sample size (10 subjects per study group) was the main limitation of this study. However, a subsequent study with a 50\% larger sample using the same combinations 4 years later showed that the submucosal route was indeed more effective in minimizing not only post-operative trismus but also swelling and pain, than intra-muscular (deltoid) injection [38]. Majid increased the number of subjects to 11 in each study group to arrive at a second report, which also studied the effect of submucosal and intramuscular injection of dexamethasone after third molar surgery on patients' clinical sequalae. He added the measurement on the quality of life (QoL) [27]. The results were found to be similar to the earlier study, where both submucosal and intramuscular injections of $4 \mathrm{mg}$ dexamethasone given just after surgery resulted in significant improvement of swelling and pain, and also in QoL measures when compared to control. Like the previous study, only the submucosal group showed significant improvement of trismus when compared with control. Majid concluded that submucosal dexamethasone offered significant positive effects on clinical and QoL recovery.

In the same year, Deo and Shetty studied the efficacy of single submucosal injection of a higher dose $(8 \mathrm{mg})$ of dexamethasone given prior to third molar surgery [28]. They found that dexamethasone was significantly effective in reducing swelling and trismus on the second day post-operative. Dexamethasone also prolonged the duration of analgesia, resulting in the dexamethasone group consuming their 
first analgesic significantly later than the control group. However, there was no overall significant difference in pain perception between the study group and saline control. The limitation of this study was the fact that both groups of samples were given ice-pack and ibuprofen post-operatively. This may explain why no difference in pain perception was observed post-operatively, as the anti-inflammatory effect of ibuprofen is more efficacious for pain control purposes. Elsewhere, a randomized controlled trial was carried out by Antunes et al. to compare the efficacy of $8 \mathrm{mg}$ dexamethasone administered using 2 different routes, oral versus intramuscular (masseter) injection [29]. They found no significant differences between the two dexamethasone groups in reducing post-operative pain, swelling and trismus, where both modes were better than control group. The advantage of intramuscular masseter injection would be its close proximity to the surgical site, hence possibly providing some localized effect although it cannot be ruled out that this injection provided a systemic effect equal to oral dosing [29].

In 2012, Boonsiriseth et al. reported an almost similar approach in a study that compared the efficacy of intramuscular dexamethasone and oral dexamethasone in reducing the sequelae of third molar surgery [30]. The only difference was that the intramuscular injection was given into the deltoid muscle which was a distance from the oral cavity. Hence, the effect of dexamethasone was purely systemic. They found that no significant difference was noted between both groups, similar to the report by Antunes et al. [29]. Based on the findings of these 2 studies, it appears that the anti-inflammatory effect of intramuscular dexamethasone was more likely to be of systemic rather than local effect, as the absorption of dexamethasone via the masseter and deltoid muscle produced similar effects. Klongnoi et al. conducted a study to investigate the effects of intramuscular dexamethasone given $1 \mathrm{~h}$ pre-emptive in reducing pain, swelling and trismus [31]. Pain and swelling were significantly reduced with corticosteroid but it was not effective in reducing trismus [31]. Although intramuscular administration into the deltoid muscle was easy and accessible, it is painful, and absorption varies depending on local blood flow.

In the following year, Bortoluzzi et al. studied the incidence of post-operative complications of alveolar osteitis and alveolar infection, in addition to the usual sequalae following third molar surgery [32]. They used two drugs, namely oral $8 \mathrm{mg}$ dexamethasone and $2 \mathrm{~g}$ amoxicillin, in various combinations where either of both the drugs can be present or absent altogether. In essence, there was a group with both drugs present, 1 group with dexamethasone, 1 group with amoxicillin and 1 group where neither drugs were given. Surprisingly, they found no significant difference between groups in terms of post-operative swelling, pain and trimus. This may have been caused by the use an ice-pack and the prescription of paracetamol and sodium diclofenac as post-operative analgesics. In addition, the measure of swelling and trismus were based on patient reporting. As no clear benefit could be observed, they recommended that antibiotic and corticoid prophylaxis should not be administered routinely for third molar surgeries involving healthy and young patients.

In the same year, Nair et al. and Warraich et al. conducted independent studies at two different centers to evaluate the efficacy of pre-emptive $4 \mathrm{mg}$ dexamethasone given as submucosal infiltrations [33, 34]. While both authors concluded that this regime significantly 
reduced post-operative swelling, they differed in reducing pain and trismus. Warraich et al. [34] found dexamethasone was significantly beneficial in reducing pain and trismus. Their patients also reported increased satisfaction with the use of dexamethasone [34], probably because these patients suffered less from the sequelae of third molar surgery. The post-operative regime of analgesic prescribed may have contributed to the difference in the findings of trismus and pain between these 2 studies. Nair et al. prescribed diclofenac sodium $75 \mathrm{mg}$ twice a day for 3 days, while Warraich et al. prescribed ibuprofen $600 \mathrm{mg} 3$ times a day on Day 1, twice a day on Day 2 and once daily on Day 3 and Day 4. In contrast to Warraich et al.'s regime, the constant dosage in Nair et al.'s study produced sustained plasma level of analgesic which rendered better pain control and subsequently improved the ability to open the mouth in both the study and control groups. This may cause the study group to report no additional beneficial effect of dexamethasone when compared with the control.

In continuity to their earlier work, Majid and Mahmood [23] became the first researchers to compare the effect of giving post-operative dexamethasone using 5 different routes of administration, namely intramuscular injection, intravenous injection, oral tablets, submucosal injection and endo-alveolar application. They reported no significant differences among groups for all the parameters of swelling, pain and trimus in subjects given $4 \mathrm{mg}$ dexamethasone. They found that, to control swelling, the best improvement was obtained via the intravenous route, followed by the intramuscular, submucosal, oral and endo-alveolar routes in a descending order on the first post-operative day. Interestingly, they found that the endo-alveolar group showed better improvement on Day 3. In comparison, the submucosal route provided slight advantage on Day 1, although the effect on trismus was comparable among treatment groups. Again, they found that endo-alveolar dexamethasone showed a better effect on trismus at the subsequent intervals of Day 3 and Day 7. With respect to pain, intravenous administration was reported to be the best at all intervals, followed by endoalveolar, submucosal, oral and intramuscularroutes in descending order. In summary, their results seemed to favor the intravenous and endo-alveolar routes, although other means of administration appeared to provide comparable results.

In 2014, another study similar to Nair et al.'s and Warraich et al.'s was undertaken by Ehsan et al. to examine the pre-emptive effect of submucosal infiltration of $4 \mathrm{mg}$ dexamethasone on post-operative swelling and trismus only [35]. Their findings support the results reported by Deo and Shetty and Warraich et al., but Ehsan et al. did not study the effect of dexamethasone on post-operative pain and their analgesic regime was not described. In the same year, Agostinho et al. compared the effect of $4 \mathrm{mg}$ and $12 \mathrm{mg}$ dexamethasone in reducing post-operative sequelae [36]. The latter dosage was three times the lowest effective dosage of $4 \mathrm{mg}$ reported elsewhere. Their findings concurred with that reported by Grozzi et al. and Graziani et al. where a higher dosage of dexamethasone did not offer a better outcome. Thus, based on their findings, they suggested that the lowest dose possible to achieve an anti-inflammatory effect should always be prescribed.

Recently, Chaudary et al. compared the pre-emptive effect of $4 \mathrm{mg}$ intravenous dexamethasone against an oral administration of $8 \mathrm{mg}$ dexamethasone [37]. They found that 
both routes of administration were equally effective in reducing post-operative pain, swelling and trismus. This is because an oral corticosteroid such as dexamethasone at $8 \mathrm{mg}$ has a very high enteral absorption rate that is comparable with intravenous application [39]. Hence, oral dexamethasone is a good alternative to the intravenous route in patients who do not wish to receive an injection.

Over the last decade, only 1 study has looked into the effect of betamethasone. Marques et al. in 2014 studied the effect of a post-operative submucosal betamethasone $12 \mathrm{mg}$ injection on the sequelae of third molar surgery [40]. Surprisingly, betamethasone which is of the same potency as dexamethasone showed no significant effect in reducing post-operative swelling, pain and trismus at all. This finding is in contrast to that reported by Chopra et al. who studied the effects of several drugs, one of which was betamethasone, given orally three times a day following third molar surgery [6]. We disagree with the authors' proposal that tissue manipulation affected the concentration and absorption of the injected drug as one of the explanation for their findings, since the injection was given after the surgery, where no further tissue manipulation was carried out. We agree with the authors that more study on the effect of betamethasone needs to be carried out to ascertain its effects in reducing post-operative sequelae since betamethasone has the same potency as dexamethasone, and therefore should theoretically render similar results clinically.

In summary, dexamethasone has proven to be an effective agent for reducing pain, swelling and trismus to a certain degree, irrespective of the route and the timing of administration. The lowest dose possible to achieve an anti-inflammatory effect was $4 \mathrm{mg}$. No serious adverse effects, namely acute alveolar osteitis, post-operative infection and nausea, have been reported following the administration of dexamethasone in the study samples. Variations in the results may be because of differences in surgical methods, differences in individual response to treatment and differences in the methodology used.

\section{Results Involving Prednisolone}

Prednisolone and methylprednisolone have been tested in a number of studies (Table 3) $[39,41-51]$. Two reports coming from the 1970s showed that preemptive administration of intravenous methylprednisolone or oral prednisolone significantly reduced post-operative edema, pain and trismus $[52,53]$. Prednisolone and methylprednisolone are five times more potent than cortisone, with an intermediate duration of action (see Table 1). Prednisolone is available in oral, topical and injection forms, while methylprednisolone is usually administered via the intravenous or intramuscular route [41, 42]. Although the possibility of topical (endo-alveolar) application has been described for dexamethasone, this approached has yet to be attempted on prednisolone.

Throughout the last 10 years, only 2 studies have looked into the effects of prednisolone. Tiigimae-Saar et al. reported that post-operative administration of $30 \mathrm{mg}$ prednisolone relieved pain, swelling and trismus more than non-administration of prednisolone in the control group [43]. On the other hand, Kang et al. tried to determine the effect of lower doses of prednisolone on the sequelae of third molar surgery [44]. They compared the efficacy of $10 \mathrm{mg}$ and $20 \mathrm{mg}$ prednisolone taken orally in more than 200 patients. Their results showed that both dosages had no significant impact on the sequelae of surgical removal of third molars. 
Hence, they concluded that a dosage of $20 \mathrm{mg}$ or lower may not provide relief of post-operative sequelae. It is suspected that such a finding may have resulted from the use of ice-packs for 2 post-operative days and the prescription of ibuprofen $200 \mathrm{mg}$ orally preoperatively, immediately after surgery, and every $8 \mathrm{~h}$ until the third post-operative day, which masked the effect of prednisolone. In addition, this study was carried out by the use of a questionnaire with patients being asked to report changes in post-operative symptoms for 6 days [44].

There have been 12 studies that attempted to determine the effects of methylprednisolone on the sequelae of third molar surgery. In 2006, Micó-Llorens et al. conducted a study to determine the efficacy of pre-operative gluteal injection of methylprednisolone in controlling the sequelae of third molar surgery [41]. They reported that methylprednisolone significantly reduced post-operative swelling and trismus on the second post-operative day. As for post-operative pain, its significant effect was only recorded at $6 \mathrm{~h}$ post-surgery. Subsequently, the pain difference between the methylprednisolone group and control was not significant. Gluteal injection may be effective but this method may not be convenient in certain clinical settings. Two years later, the same group, now lead by Vegas-Bustamante, performed a similar study, but instead gave post-operative masseteric injection of $40 \mathrm{mg}$ methylprednisolone [42]. They found that this regime significantly reduced post-operative swelling and trismus for up to 7 days, and provided better pain control for 3 days post-operative.

In the following year, Gataa and Nemat compared the effectiveness of two modes of pre-emptive administration of $10 \mathrm{mg}$ methylprednisolone, namely enteral and submucosal injection [46]. They reported that methyprednisolone taken orally $1 \mathrm{~h}$ pre-operative was more effective than submucosal injection in controlling swelling and pain. They reasoned that this was due to the slow absorption of the injected form of methylprednisolone, coupled with its biological half-life of $18-36 \mathrm{~h}$. As pain usually peaks $6-8 \mathrm{~h}$ and edema reaches its maximum size about $36-48 \mathrm{~h}$ after third molar surgery, the injected (localized) methylprednisolone therefore has less effect due to the slower onset of its action. This suggestion, however, needs further investigation as the only other group of researchers who investigated the effectiveness of submucosal injection of methyprednisolone after them reported contradictory results. Ashraf et al. reported that submucosal injection was equally as effective as intramuscular (gluteal) injection in providing relief of swelling, pain and trismus after third molar surgery [47]. Do note, however, that they administered a high dose of $125 \mathrm{mg}$ methylprednisolone to their patients, probably because they were influenced by the dose used by Al-Khateeb et al. [55]. Besides them, the only other authors who compared the effect of submucosal and intramuscular injection were Majid and Mahmood both reporting favorable effects on swelling and pain using dexamethasone, but at a lower equivalent dose $[23,26]$.

In 2011, Kaur et al. conducted a study similar to that performed by Vegas-Bustamante et al. to evaluate the effect of a single $40 \mathrm{mg}$ dose of methylprednisolone, injected into the masseter muscle following surgical removal of impacted third molars [45]. They also reported that methylprednisolone had significantly reduced post-operative pain, swelling and trismus. The findings from 3 studies confirmed that masseteric injection is a good and effective 
way to administer methylprednisolone [41, 42, 45]. This observation was confirmed in 2013 by Chaurand-Lara and Facio-Umaña who reported that the benefit of giving a masseteric intramuscular injection of $20 \mathrm{mg}$ methylprednisolone for immediate post-operative control of pain and swelling [48]. The limitations of their study were that the site of this split mouth study was not randomized and only the subjects were blinded to the injection.

Acham et al. were the only authors who studied the effect of pre-emptive body weight-dependant doses of oral methylprednisolone in reducing post-operative pain, swelling and trismus [39]. The reason why they administered methylprednisolone orally was because of its extremely high enteral absorption rate that is comparable with intravenous application. Similar to the results obtained from previous studies using methylprednisolone, it was significantly effective in reducing all 3 post-operative sequalae, especially pain. There was significantly less pain suffered by patients given methylprednisolone throughout the 7 days of study. They acknowledged the use of NSAIDs post-operatively may partly contribute to this good result. The authors reported no adverse effect related to the drug, but the fact that patients were covered with pantoprazole made it difficult to find any gastrointestinal effect of relatively high doses of methylprednisolone.

Koçer et al. in 2014 attempted to determine the best route for prescribing effective methylprednisolone [49]. They compared the efficacy of $20 \mathrm{mg}$ methylprednisolone in reducing post-operative swelling and trismus delivered through masseteric intramuscular injection, oral intake and intravenous delivery. They reported less trismus in all patients given methylprednisolone regardless of its forms or routes. Of these routes, masseteric (local) injection proved to be superior in reducing swelling but trismus was slightly better controlled by intravenous methylprednisolone, although this finding was not statistically significant. From these findings, we can deduce that masseteric injection of methylprednisolone would make a good mode of administration taking into consideration the ease of administration, patient comfort and its better post-operative effect [49]. Results from this study reconfirmed the findings of 4 previous studies.

Instead of the mode of administration, Vyas et al. studied the timing of drug administration [51]. They compared the pre-emptive and post-operative effects of intramuscular methylprednisolone and reported that pre-emptive administration of $40 \mathrm{mg}$ methylprednisolone was significantly better in reducing facial swelling and trismus and, to some extent, pain [51]. Pre-emptive methylprednsolone provided early advantage in pain relief, but later was not different than post-operative intramuscular injection as the latter become redistributed in the circulation. These findings were not unexpected as corticosteroids were given $1 \mathrm{~h}$ before the onset of inflammatory response, thereby allowing adequate time to reach the target site to prevent the activation of the arachidonic acid pathway following injury [39]. Methylprednisolone acetate used in this study has a sustained release effect due to its formulation, thus providing a prolonged anti-inflammatory effect that prevented rebound swelling from happening. In this study, no negative control was used, therefore anti-inflammatory effect of post-operative administration of methylprednisolone cannot be entirely appreciated, unlike in the reports by Vegas-Bustamante et al. [42] and Kaur et al. [45]. 
Selvaraj et al. in 2014, compared different sites for intramuscular injection. They injected $40 \mathrm{mg}$ methylprednisolone into masseter and gluteus muscles of the same subjects undergoing a cross over study and found no significant difference in the effects when using these two sites [50]. Both sites of administration were equally effective in reducing patients' post-operative sequalae of swelling, pain and trismus. This finding supports the suggestion of the systemic effect of intramuscular injections of corticosteroids as shown by Boonsiriseth et al. [30] and Antunes et al. [29], who found that the absorption of drugs via the masseter and deltoid muscles produced the same effect as oral intake. This again supports the suggestion that the effect of masseter muscle injection is systemic instead of localized. So, if given a choice between the masseter and other sites, it is more likely that the masseter will be the preferred site of injection as it is more convenient and comfortable to the surgeons and patients. It also holds the advantage of being a painless site for steroid injection as the masseteric muscle usually gets anesthetized during the provision of local anesthetic agents for third molar surgery.

In summary, prednisolone and methylprednisolone have proven to be effective agents for reducing swelling and trismus, and to some extent pain, irrespective of the route and the timing of administration. The lowest dose possible to achieve anti-inflammatory effect appears to be $40 \mathrm{mg}$. No serious adverse effects, namely acute alveolar osteitis, post-operative infection and nausea have been reported following the administration of prednisolone or methylprednisolone in the study samples. Variations in the results obtained may be the results of differences in surgical approaches, differences in individual response to treatment and differences in the methodology adopted.

\section{Result Comparing Different \\ Corticosteroids}

For some unknown reasons, there are few studies that have attempted to compare the efficacy of two different groups of corticosteroids (Table 4). So far, there have been 3 studies undertaken to compare the efficacy of dexamethasone versus methylprednisolone in controlling the post-operative sequalae of third molar surgery [54, 56, 58]. In 2012, Loganathan and Srinivasan [56] compared the efficacy of single doses of methylprednisolone (40 mg) and dexamethasone (4 mg) injected into the masseter muscle about $15 \mathrm{~min}$ prior to surgery. They found no significant difference between the two groups in alleviating the post-operative sequale of third molar surgery.

In contrast, Alcântara et al. and Darwade et al. reported different findings [54, 57]. Both studies compared the efficacy of oral administration of $8 \mathrm{mg}$ dexamethasone against $40 \mathrm{mg}$ methylprednisolone in reducing post-operative discomforts. These dosages were chosen as they were approximately equivalent to $200 \mathrm{mg}$ of cortisol. Both studies reported significant reductions in swelling and trismus in the dexamethasone group as compared to the methylprednisolone group. The former group was also reported to have less pain when compared to the methylprednisolone group, although the difference was not statistically significant. The beneficial effect of dexamethasone was due to its longer duration of action and greater potency compared to methylprednisolone.

Most recently, Zerener et al. [58] has compared the post-operative submucosal injection of dexamethasone and triamcinolone acetonide. This is the only study that has tried to determine the effect of injecting 
triamcinolone acetonide submucosally. In agreement with many other studies, both corticosteroids were significantly better in controlling post-operative swelling. Dexamethasone was better in reducing post-operative pain and trismus on the first and third post-operative days, while triamcinolone acetonide controlled pain better on the third and seventh post-operative days compared to control. Triamcinolone acetonide significantly reduced trismus throughout the period of assessment compared to control, while dexamethasone was effective during the early post-operative days. The difference in the time of best effect may have resulted from the different half-life of each steroid. However, there was no significant difference between the two corticosteroids in reducing post-operative swelling, pain and trismus. Nevertheless, the authors suggested that triamcinolone acetonide makes a good alternative to dexamethasone in controlling the post-operative sequale of third molar surgery.

In summary, more studies should be carried out in the future to compare different types of corticosteroids to reveal the one with the lowest effective dosage and easiest route of administration for use in routine oral surgical procedures. Dexamethasone appears to be more potent and effective than methylpredinsolone clinically. The use of triamcinolone acetonide though is promising, and needs further randomized and control studies. A summary of the outcomes of various researches cited here is presented in Tables 2, 3 and 4.

\section{DISCUSSION}

Altogether, this review found that a single administration of corticosteroids was often effective in reducing post-operative pain, swelling and trimus, in contrast to previous reports that emphasized the need for pulse therapy or a longer duration of dosing to extend the benefits of the drug [12, 19, 52]. Although doses of corticosteroids will usually clear the blood stream in less than $24 \mathrm{~h}$, the immunosuppresive anti inflammatory effects may persist up to 3 days, thus explaining why even a single dose is adequate for third molar surgery [59]. However, there have been three reports that found that corticosteroids were not better than negative control [32, 40,44]. One possible explanation as to why these studies found that negative control was equally as good is possibly because the patients were stimulated through the hypothalamic-pituitary-adrenocortical pathways to increase their secretion of steroids, mostly hydrocortisone, during third molar surgery [59]. Another reason is the suboptimal dose provided, as reported by Kang et al. [44]. One way to determine the level of corticosteroids in the body is to measure them; another way is by checking the peripheral eosinophil count, as a study by Thorn et al. found that a fall in the peripheral eosinophil count is one of the most significant effects of cortisones on the cellular elements of the blood [60]. The magnitude of the fall varied with the dosage and route of administration. Ross and White reported the monitoring of peripheral eosinophil counts in their third molar study in 1958 [18], but no other researchers have done so since then. They reported an interesting fact discovered in the control group in which 6 patients (out of 22) were found to have a better than $50 \%$ reduction in their eosinophil counts, and, interestingly enough, all of these patients fell in the moderate edema group. This suggested that those patients produced excessive corticosteroids as a reaction to the trauma of surgery, hence resulting in less facial swelling. 
Hydrocortisone (cortisol) is the natural corticosteroid produced by the body, with normal daily production in a normal adult being between 15 and $30 \mathrm{mg}$, but up to $300 \mathrm{mg}$ can be supplied in times of crisis $[12,59,61]$. To achieve an anti inflammatory effect, corticosteroids have to be given at higher doses, above the basal secretion. However, there was not one single study that can answer the question on the best dosage, best route of administration and best time to provide corticosteroids. One fact that remains certain is that Kang et al. [44] in 2010 showed that prednisolone in doses of less than $20 \mathrm{mg}$ was not effective. Therefore, a higher dose is suggested for clinical use. There follows a detailed discussion on the route of administration, dosage, and timing of the surgery, as well as the effects of corticosteroids on swelling, trismus and pain.

\section{Route of Administration}

Although intravenous administration affords excellent and immediate plasma drug levels, this route is infrequently used in an outpatient clinical setting, unless patients are receiving intravenous sedation at the same time [19]. In fact, throughout the last 10 years, only 3 studies looked into the effectiveness of the intravenous route as a means to deliver corticosteroids. Chaudary et al. compared the pre-emptive effect of $4 \mathrm{mg}$ intravenous dexamethasone against an oral administration of $8 \mathrm{mg}$ dexamethasone and found that both routes of administration were equally effective in reducing post-operative swelling, pain and trismus [37]. Do note, however, that the dosage of the oral route was twice the intravenous dose of dexamethasone administered. A similar effect has been reported by Majid and
Mahmood who, in 2013, compared the intravenous route against intramuscular injection, submucosal injection, endo-alveolar application and per oral intake [23]. Koçer et al. on the other hand showed that the intravenous route was more effective than intramuscular and oral intake [49]. This finding is in contrast to a report 60 years ago, which stated that the oral route was found to be as effective as the intravenous route [60]. This finding also contradicts earlier reports that suggested supplementing intravenous corticosteroids with post-operative oral doses up to 1 day to maximize the beneficial effect of corticosteroids [19].

Two other routes of administration that involve the use of needle and syringe are the intramuscular and subcutaneous routes. Studies have shown that intramuscular injections are effective irrespective of the site of injection [23, 26, 27, 29-31, 41, 42, 45, $47-49,51]$. However, injecting patients at the gluteus or deltoid muscle may not be a convenient procedure due to religion and cultural restrictions. In addition, patients may decline receiving injections away from the oral cavity due to needlephobia. In such cases, the masseteric muscle makes a good alternative site. This site of administration of the corticosteroid is convenient for the surgeon, since the injection is carried out close to the surgical area. For the patient, this injection is painless as it is usually given after the area has achieved anesthesia. In addition, its effectiveness does not depend on the patient's compliance as in the case of enteral route $[29,42,45,46,48]$. Several studies have shown that corticosteroids given submucosally are as effective as those administered via the intramuscular route [23, 26, 27, 38, 47]. A recent meta-analysis study confirmed the effectiveness of submucal 
injection of dexamethasone [62] in relieving post-operative pain and swelling, but not trismus. There was one study that, however, found submucosal injection was less effective when compared to oral route [46]. This difference may have arisen from the fact that oral corticosteroids were given $1 \mathrm{~h}$ pre-emptive, hence giving it ample time to be circulated into the body in comparison to the submucosal injection. Nevertheless, due to its proximity to the surgical site, the submucosally administered corticosteroids will eventually be able to act on eicosanoids that are present, hence preventing subsequent inflammatory processes.

Another approach to introduce corticosteroids directly to the surgical wound was the endo-alveolar approach. So far, there were only two study that reported the effect of this approach, which apparently was better than submucosal injection $[22,23]$. It has been shown that a locally applied glucocorticoid has direct inhibitory effect on signal transmission in nociceptive C-fibers and ectopic neuroma discharge in injured nerve [63]. Similar mechanism may explain for the improvement in pain relief as reported by the two research groups [21]. Although topical (endo-alveolar) application has been described for dexamethasone, this approached has yet to be attempted on prednisolone.

Of all routes, the oral route is the most convenient and perhaps most acceptable to the patient. Orally administered corticosteroids has been shown to undergo rapid and almost complete absorption, but its efficacy and time taken to achieve therapeutic plasma level is questionable when compared with parenteral administration [63]. Previous studies reported that oral corticosteroids are best given at least 3-4 h before surgery [19]. However, current studies show that preemptive intake $1 \mathrm{~h}$ before surgery was the preferred choice and was able to render similar desired effect $[25,29,37,39,46]$. Nevertheless, the study by Tiigamae-Saar et al. [43] and Boonsiriseth et al. [30] showed that post-operative intake of a single dose of corticosteroids or over one day was equally effective. This finding was supported by Majid and Mahmood [23]. Although this route is the most convenient way to provide corticosteroids, it may not be practical for patients who are fasted for the removal of third molars under general anesthesia. This is because the use of oral forms might cause gastrointestinal upset, unless it is taken with food [59]. In fact, oral intake of corticosteroids is contraindicated for patients with gastrointestinal problem; hence the need to utilize other routes described above.

\section{Timing}

Based on the articles reviewed, it seems that corticosteroids were equally effective regardless of the timing of their administration. However, a recent study by Vyas et al. [51] showed that pre-emptive administration was significantly better than those given post-operatively. Their finding also concurred with the conclusion made by two previous reviews $[19,20]$. This advantage is based on the fact that corticosteroids should be given before the onset of the inflammatory process. Post-operative administration may only prevent further propagation of inflammation but is unable to reverse inflammation that has occurred. Nevertheless, more studies on the timing of administration of different corticosteroids are required to confirm the current findings, as two groups of researchers have reported that post-operative intake of corticosteroids was as effective [23, 41]. 


\section{Effects on post-operative Sequalae}

Although results from various studies were inconsistent especially in reducing post-operative pain and trismus (see below), corticosteroids consistently produced a favourable effect in reducing edema, i.e. post-operative swelling. This observation has been reported in 22 out of 29 (75.9\%) studies that showed a reduced swelling against negative control [22-29, 31, 33-35, 39, 41-43, $45-49$, 51]. It has to be borne in mind, though, that all these studies used linear measurement to assess facial swelling. This was done by marking a few points on the face; for example, the outer canthus of the eye, angle of mandible, corner of mouth, tragus, and symphysis, and a linear distance between two points were measured. This technique, although easy and cost-effective, is subjected to errors during assessment. This may explain the inconsistent findings in two studies $[32,40]$. In fact, one study with no significant results on swelling used patient feedback as a tool of measurement [44]. Nevertheless, it can be concluded that all these studies confirm to a certain degree the anti-inflammatory effect of various corticosteroids administered in different dosing regimens and administration routes to lessen swelling, and to some extent pain and trismus, following third molar surgery.

Trismus can be a manifestation of pain, swelling or both. Eighteen out of 25 (72.0\%) studies reported improved mouth opening $[22,23,25-29,34,35,39,41-43,45-47,49$, 51]. Five groups of researchers found that corticosteroids which were effective in reducing swelling failed to provide similar beneficial effects against trismus $[24,31,33,48]$. The dosage of corticosteroids given to reduce trismus may be a critical factor. One group of researchers found that oral prednisolone of less than $20 \mathrm{mg}$ was not effective in reducing trismus [44], while two other groups [39, 43] proved that oral prednisolone doses of more than $20 \mathrm{mg}$ were significantly effective. All different modes of administration have been shown to be equally effective in reducing trismus.

One has to remember that inflammation may only be one of the many factors leading to trismus after a third molar surgery. Trismus may also result from the inhibitory effect of muscle pain, either from the masseter muscle (due to its proximity to the surgical site) or the lateral pterygoid muscle (due to prolonged mouth opening during surgery or stress during extraction). These muscles could have acted as a feedback muscle to induce an inhibitory effect on the motor cortex excitability, as reported on other parts of the body [64]. This inhibitory effect is thought to prevent further movement of the injured site and to protect the painful muscle. However, applying this mechanism to the trigeminothalamic system may not be as straightforward since both trigeminothalamic and spinothalamic systems have different complex functions [65]. Nevertheless, this should be a factor to reckon with. Other factors that may exacerbate trismus include prolonged surgical time, traumatic extraction and accidental injection of a local anesthetic agent into the medial pterygoid muscle. None of these confounding factors have been addressed in any of the studies reviewed here.

Some reduction of post-operative pain is generally expected following a reduction of edema, in addition to the corticosteroids' inhibitory effects on prostaglandins. Of the 24 studies that looked into the effect of corticosteroids in reducing post-operative pain after third molar removal, 16 (66.7\%) reported improved pain relief $[22,23,26,27,29$, $39,42,43,45-48]$. Fifty-six percent of these 
reports were associated with the use of methylprednisolone as an anti-inflammatory agent. This gives an impression that methylprednisolone is the corticosteroid with a better analgesic effect. However, a recent report found that dexamethasone appeared to have a slight advantage over methylpredinsolone when both agents were compared in a clinical trial. Alçantara et al. [54] showed that $8 \mathrm{mg}$ dexamethasone was superior to $40 \mathrm{mg}$ methylprednisolone in reducing post-operative pain. In other studies, the inconsistent effect on pain may lie in the dosage of corticosteroids given. One study found that methylprednisolone with dosages below $20 \mathrm{mg}$ appeared to be ineffective for post-operative pain relief [44]. In comparison, many studies have shown that methylprednisolone, when given in higher doses regardless of route of delivery, showed a consistent positive result in reducing pain [39, 41-43, 45-48, 51]. With regard to dexamethasone, only 7 studies $[22,23,26,27$, $29,31,34$ ] reported its ability to relieve pain while another 6 studies showed no significant effect on pain management, as administered using various doses and by different routes of administration $[24,25,27,32,33,40]$.

Although 16 studies have shown some reduction of pain with corticosteroids use, the actual mechanism of this effect has yet to be understood. In fact, earlier studies reported that corticosteroids alone have shown no clinically significant analgesic effect [3, 66, 67]. Worse, the use of corticosteroids might increase the patient's reaction to pain by suppressing $\beta$-endorphin levels [68]. It is well known that analgesics such as paracetamol and NSAIDs have a ceiling of analgesic effect, and may not be sufficient as monotherapy after third molar surgery. As corticosteroids act on the prostaglandin system differently than NSAIDs and have other anti-inflammatory effects, better analgesia had been achieved when corticosteroids were added to NSAIDs [69-71]. The analgesic effect of corticosteroids is suspected to be mediated by anti-inflammatory and immune suppressive effects [72]. Their anti-inflammatory action results in decreased production of various inflammatory mediators that play a major role in amplifying and maintaining of pain perception. In addition, swelling that results from surgery causes tissue tension which leads to additional tension-induced pain [11]. The ability of corticosteroids to reduce swelling may amplify their analgesic effect by lessening pain that arises from tissue tension. This suggestion concurs with the opinion of Messer and Keller who stated that pain was related to swelling and that, if swelling could be controlled, the pain would be minimal [3].

The apparent interactions between the mechanisms of the action of NSAIDs and steroids suggests that co-therapy may provide beneficial inflammatory and pain relief in the absence of side effects [70, 71, 73]. Recently, Jarrah et al. performed a study that confirmed the synergistic effect of corticosteroids (dexamethasone) with ibuprofen in controlling post-operative pain and trismus, as opposed to corticosteroid alone [74].

It has to be noted that, in the studies reviewed, pain was assessed subjectively and was not the only primary outcome measured. As a result of this, pain outcomes after third molar surgeries varied. Pain is also dependant on several factors such as surgical trauma and the individual's pain threshold and psychological well-being [3]. Lastly, corticosteroids have also been reported to have synergistic effects with local anesthesia given for surgery [75]. So, it is unclear at this point whether the reduced pain experienced by patients has arisen from their 
synergistic effect with local anesthetic agents given or from their synergistic effect with the analgesics prescribed. These suggestions warrant further detailed study with pain as the primary outcome to confirm the current observation.

The adverse effects of a single dose of corticosteroid appear to be very low as all studies reviewed hardly reported any adverse effects. This concurs with the finding of previous studies that have demonstrated the safety of a a single dose or short-term protocol of less than 3-5 days [59, 61]. In fact, Valergakis et al. [76] observed no increase in the number of complications, even with extended post-operative use up to 5 days at $12 \mathrm{mg}$ per day of steroids, including dexamethasone. In comparison, the side effects of prolonged corticosteroid use are well known, and they include increased appetite, excessive weight gain, development of abdominal girth, insomnia, increased sweating, mild hirsutism, cutaneous purpura, and slight facial rounding [77], none of which are expected to occur following their use for third molar surgery. These adverse effects are often cited as the reason against the use of corticosteroids in routine clinical dental practice [13]. It is about time dentists rethink their reluctance to use short-term corticosteroids, especially with just one dose given peri-operatively.

\section{CONCLUSION}

From these studies, it can be summarized that the use of corticosteroids in third molar surgery appears promising in reducing post-operative discomforts or sequelae. Fourteen studies reported the benefit of corticosteroids on all 3 sequelae, with $71.4 \%$ resulting from methylprednisolone use. It is almost certain that swelling and to some extent trismus will be significantly reduced with the use of corticosteroids. It appears that the potential analgesic effect of corticosteroids holds promise to enhance their further acceptance into routine dental practice, although their role in pain control remains debatable. More studies should therefore be carried out to confirm if the analgesic effect results from the synergistic effects with NSAIDs and/or local anesthetic agents. Assessment of the sequelae should be done with more accurate and precise assessment tools so that the results of these future studies will have an impact on the best route and corticosteroids to be used, taking into consideration its efficacy and side effects as well as cost and whether its usage is economically feasible to be adopted in routine practice.

\section{ACKNOWLEDGMENTS}

This work was supported by the University of Malaya's High Impact Research Grant UM.C/ $625 / 1 / \mathrm{HIR} / \mathrm{MOHE} / 05$. No funding or sponsorship was received for the publication of this article. The authors would like to acknowledge Professor M. Tony Pogrel for the input, advice and critical comments given during the preparation of this manuscript. All named authors meet the International Committee of Medical Journal Editors (ICMJE) criteria for authorship for this manuscript, take responsibility for the integrity of the work as a whole, and have given final approval for the version to be published.

Disclosures. Wei Cheong Ngeow and Daniel Lim have nothing to disclose.

Compliance with Ethics Guidelines. This article is based on previously conducted studies and does not involve any new studies 
of human or animal subjects performed by any of the authors.

Open Access. This article is distributed under the terms of the Creative Commons Attribution-NonCommercial 4.0 International License (http://creativecommons.org/licenses/ by-nc/4.0/), which permits any noncommercial use, distribution, and reproduction in any medium, provided you give appropriate credit to the original author(s) and the source, provide a link to the Creative Commons license, and indicate if changes were made.

\section{REFERENCES}

1. McGrath C, Comfort MB, Lo EC. Changes in life quality following third molar surgery-the immediate post operative period. $\mathrm{Br}$ Dent $\mathrm{J}$. 2003;194:265-8.

2. Kumar V, Abbas AK, Fausto N, Aster JC. Robbins and cotran pathologic basis of disease 8th edn. Philadelphia: Elsevier; 2010.

3. Messer EJ, Keller JJ. The use of intraoral dexamethasone after extraction of mandibular third molars. Oral Surg Oral Med Oral Pathol. 1975;40(5):594-8.

4. Kirmeier R, Truschnegg A, Payer M, Acham S, Schulz K, Jakse N. Evaluation of a muscle relaxant on sequelae of third molar surgery: a pilot study. Oral Surg Oral Med Oral Pathol Oral Radiol Endod. 2007;104:e8-14.

5. Markovic A, Todorovic L. Effectiveness of dexamethasone and low-power laser in minimizing edema after third molar surgery: a clinical trial. Int $\mathrm{J}$ Oral Maxillofac Surg. 2007;36:226-9.

6. Chopra D, Rehan HS, Mehra P, Kakkar AK. A randomized, doubleblind, placebo-controlled study comparing the efficacy and safety of paracetamol, serratiopeptidase, ibuprofen and betamethasone using the dental impaction pain model. Int J Oral Maxillofac Surg. 2009;38:350-5.

7. Hench PS, Kendall EC, Slocumb CH, Polley HF. The effect of a hormone of the adrenal cortex (17-hydroxy-II-dehydrocorticosterone:compound E) and of pituitary adrenocorticotropic hormone on rheumatoid arthritis. (Prelim. Rept.). Proc Staff Meetings Mayo Clinic. 1949;24:181-97.

8. Arth GE, Johnston DBR, Fried J, Spooncer WW, Hoff DR, Sarett LH. 16-Methylated steroids. I. 16 $\alpha$-Methyl analogues of cortisone, a new family of anti-inflammatory steroids. J Am Chem Soc. 1958;80:3160.

9. Arth GE, Fried J, Johnston DBR, Hoff DR, Sarett LH, Silber RH, Stoerck HC, Winter CA. 16-Methylated steroids. II. $16 \alpha$-Methyl analogues of cortisone, a new family of anti-inflammatory steroids: $9 \alpha$-halo derivatives. J Am Chem Soc. 1958;80:3161.

10. Linenberg WB. The clinical evaluation of dexamethasone in oral surgery. Oral Surg Oral Med Oral Pathol. 1965;20:6.

11. Shaikh S, Verma $H$, Yadav $N$, Jauhari $M$, Bullangowda J. Applications of steroid in clinical practice: a review. ISRN Anesthesiology. 2012, Article ID 985495, doi:10.5402/2012/985495.

12. Montgomery MT, Hogg JP, Roberts DL, Redding SW. The use of glucocorticosteroids to lessen the inflammatory sequelae following third molar surgery. J Oral Maxillofac Surg. 1990;48:179-87.

13. Ata-Ali J, Ata-Ali F, Peñarrocha-Oltra D, Peñarrocha M. Corticosteroids use in controlling pain, swelling and trismus after lower third molar surgery. J Clin Exp Dent. 2011;3(5):e469-75.

14. Strean LP. The possible role of cortisone in dentistry. N Y J Dent. 1951;22:102-4.

15. Strean LP, Horton C. Hydrocortisone in dental practice. Dent Digest. 1954;59:8-16.

16. Spies TD, Dreizen S, Stone RE, Garcia-Lopez G, Lopez-Toca R, Reboredo A. A clinical appraisal of ACTH and cortisone as therapeutic agents in dental medicine. Oral Surg Oral Med Oral Pathol. 1952;5(1):25-40.

17. Kenny FA. Editorial \& clinical observation. J Oral Surg. 1954;12:314.

18. Ross R, White CP. Evaluation of hydrocortisone in prevention of post-operative complications after oral surgery: a preliminary report. J Oral Surg. 1958;16:220-6.

19. Alexander R, Throndson R. A review of perioperative corticosteroid use in dentoalveolar surgery. Oral Surg Oral Med Oral Pathol Oral Radiol Endod. 2000;90:406-15.

20. Herrera-Briones FJ, Prados Sánchez E, Reyes Botella C, Vallecillo Capilla M. Update on the use of corticosteroids in third molar surgery: systematic 
review of the literature. Oral Surg Oral Med Oral Pathol Oral Radiol. 2013;116(5):e342-51.

21. Beirne OR. Corticosteroids decrease pain, swelling and trismus. Evid Based Dent. 2013;14:111.

22. Graziani F, D'Aiuto F, Arduino PG, Tonelli M, Gabriele M. Perioperative dexamethasone reduces post-surgical sequelae of wisdom tooth removal. A split-mouth randomized double-masked clinical trial. Int J Oral Maxillofac Surg. 2006;35:241-6.

23. Majid OW, Mahmood WK. Use of dexamethasone to minimise post-operative sequelae after third molar surgery: comparison of five different routes of administration. Oral Surg. 2013;6:200-8.

24. Grossi GB, Maiorana C, Garramone RA, Borgonovo A, Beretta M, Farronato D, et al. Effect of submucosal injection of dexamethasone on post-operative discomfort after third molar surgery: a prospective study. J Oral Maxillofac Surg 2007;65:2218-26.

25. Filho JRL, Maurette PE, Allais M, Cotinho M, Fernandes C. Clinical comparative study of the effectiveness of two dosages of dexamethasone to control post-operative swelling, trismus and pain after the surgical extraction of mandibular impacted third molars. Med Oral Patol Oral Cir Bucal. 2008;13(2):E129-32.

26. Majid OW, Mahmood WK. Effect of submucosal and intramuscular dexamethasone on post-operative sequelae after third molar surgery: comparative study. $\mathrm{Br} \mathrm{J}$ Oral Maxillofac Surg. 2011;49:647-52.

27. Majid OW. Submucosal dexamethasone injection improves quality of life measures after third molar surgery: a comparative study. J Oral Maxillofac Surg. 2011;69:2289-97.

28. Deo SP, Shetty P. Effect of submucosal injection of dexamethasone on post-operative sequelae of third molar surgery. J Nepal Med Assoc. 2011;51(182):71-7.

29. Antunes AA, Avelar RL, Neto ECM, Frota R, Dias E. Effect of two routes of administration of dexamethasone on pain, edema, and trismus in impacted lower third molar surgery. Oral Maxillofac Surg. 2011;15:217-23.

30. Boonsiriseth K, Klongnoi B, Sirintawat N, Saengsirinavin C, Wongsirichat N. Comparative study of the effect of dexamethasone injection and consumption in lower third molar surgery. Int J Oral Maxillofac Surg. 2012;41(2):244-7.

31. Klongnoi B, Kaewpradub P, Boonsiriseth K, Wongsirichat N. Effect of single dose preoperative intramuscular dexamethasone injection on lower impacted third molar surgery. Int J Oral Maxillofac Surg. 2012;41:376-9.

32. Bortoluzzi MC, Capella DL, Barbieri T, Plagiarini M, Cavalier T, Manfro R. A single dose of amoxicillin and dexamethasone for prevention of post-operative complications in third molar surgery: a randomized, double-blind, placebo controlled clinical trial. J Clin Med Res. 2013;5(1):26-33.

33. Nair RB, Rahman NMM, Ummar M, Hafiz KAA, Isaac JK, Sameer KM. Effect of submucosal injection of dexamethasone on post-operative discomfort after third molar surgery: a prospective study. J Contemp Dent Pract. 2013;14(3):401-4.

34. Warraich R, Faisal M, Rana M, Shaheen A, Gellrich N-C, Rana M. Evaluation of post-operative discomfort following third molar surgery using submucosal dexamethasone-a randomized observer blind prospective study. Oral Surg Oral Med Oral Pathol Oral Radiol. 2013;116:16-22.

35. Ehsan A, Bukhairi SGA, Ashar AM, Junaid M. Effects of pre-operative submucosal dexamethasone injection on the post-operative swelling and trismus following surgical extraction of mandibular third molar. J Coll Physicians Surg Pak. 2014;24(7):489-92.

36. Agostinho CN, da Silva VC, Maia Filho EM, Cruz ML, Bastos EG. The efficacy of 2 different doses of dexamethasone to control post-operative swelling, trismus and pain after third molar extractions. Gen Dent. 2014;62(6):e1-5.

37. Chaudary PD, Rastogi S, Gupta P, Indra BN, Thomas R, Choudhury R. Pre-emptive effect of dexamethasone injection and consumption on post-operative swelling, pain, and trismus after third molar surgery. A prospective, double blind and randomized study. J Oral Biol Craniofac Res. 2015;5:21-27.

38. Gopalakrishnan V, Darekar HS, Sahoo NK. Effectiveness of submucosal $\mathrm{v} / \mathrm{s}$ intramuscular dexamethasone in mandibular third molar surgeries. IJMSCI. 2015;2(1):648-55.

39. Acham S, Klampfl A, Truschnegg A, Kirmeier R, Sandner-Kiesling A, Jakse N. Beneficial effect of methylprednisolone after mandibular third molar surgery: a randomized, double-blind, placebo-controlled split-mouth trial. Clin Oral Invest. 2013;17:1693-700.

40. Marques J, Pié-Sánchez J, Figueiredo R, Valmaseda-Castellón E, Gay-Escoda C. Effect of the local administration of betamethasone on pain, swelling and trismus after impacted lower 
third molar extraction. A randomized, triple blinded, controlled trial. Med Oral Patol Oral Cir Bucal. 2014;19(1):e49-54.

41. Micó-Llorens JM, Satorres-Nieto M, Gargallo-Albiol J, Arnabat-Domínguez J, Berini-Aytés L, Gay-Escoda C. Efficacy of methylprednisolone in controlling complications after impacted lower third molar surgical extraction. Eur J Clin Pharmacol. 2006;62:693-8.

42. Vegas-Bustamante E, Micó-Llorens J, Gargallo-Albiol J, Satorres-Nieto M, Berini-Aytes L, Gay-Escoda C. Efficacy of methylprednisolone injected into the masseter muscle following the surgical extraction of impacted lower third molars. Int J Oral Maxillofac Surg. 2008;37:260-3.

43. Tiigimae-Saar J, Leibur E, Tamme T. The effect of prednisolone on reduction of complaints after impacted third molar removal. Stomatologija. 2010;12(1):17-22.

44. Kang S-H, Choi Y-S, Byun I-Y, Kim M-K. Effect of preoperative prednisolone on clinical post-operative symptoms after surgical extractions of mandibular third molars. Aus Dent J. 2010;55:462-7.

45. Kaur J, Sandhu S, Kaur T, Bhullar RS, Sandhu Y, Singh P. Effect of methylprednisolone on post-operative pain, swelling and trismus following the surgical removal of bilateral impacted mandibular third molars. Ind J Comp Dent Care. 2011;1(1):36-42.

46. Gataa IS, Nemat AH. Evaluation of the effectiveness of two methods using methylprednisolone on post-operative sequelae following lower third molar surgery. Kufa Med J. 2009;12(2):257-66.

47. Ashraf J, Yaqoob A, Yaqoob G, Ahad M, Rasheed N, Yaqoob M. Evaluation and comparison of locally infiltrated methylprednisolone and intramuscularly injected methylprednisolone in controlling the post-operative sequelae of impacted mandibular third molar extraction- in vivo study. IJRID. 2014;4(3):98-116.

48. Chaurand-Lara J, Facio-Umaña JA. Methylprednisolone injection following the surgical extraction of impacted lower third molars: a split-mouth study. Open J Stomatol. 2013;3:192-6.

49. Koçer G, Yuce E, Tuzuner Oncul A, Dereci O, Koskan O. Effect of the route of administration of methylprednisolone on edema and trismus in impacted lower third molar surgery. Int J Oral Maxillofac Surg. 2014;43:639-43.

50. Selvaraj L, Rao SH, Lankupalli AS. Comparison of efficacy of methylprednisolone injection into masseter muscle versus gluteal muscle for surgical removal of impacted lower third molar. J Maxillofac Oral Surg. 2014;13(4):495-8.

51. Vyas N, Agarwal S, Shah N, Patel D. Aapaliya P. Effect of single dose intramuscular methylprednisolone injection into the masseter muscle on the surgical extraction of impacted lower third molars: a randomized controlled trial. Kathmand Univ Med J 2014;12(45):4-8.

52. Huffman GG. Use of methylprednisolone sodium succinate to reduce post-operative edema after removal of impacted third molars. J Oral Surg. 1977;35:198-9.

53. Caci F, Gluck GM. Double blind study of prednisolone and papase as inhibitors of complications after oral surgery. J Am Dent Assoc. 1976;93(2):325-7.

54. Alcântara CEP, Faici SGM, Oliveria-Ferreira F, Santos CRR, Pinheiro MLP. Pre-emptive effect of dexamethasone and methylprednisolone on pain, swelling, and trismus after third molar surgery: a split-mouth randomized triple-blind clinical trial. Int J Oral Maxillofac Surg. 2014;43: 93-8.

55. Al-Khateeb TL, Marouf HA, Mahmood MA. Clinical evaluation of dexamethasone vs. methylprednisolone for reducing post-operative inflammatory sequalae following third molar surgery. Saudi Dent J. 1996;8:13-8.

56. Loganathan S, Srinivasan H. A comparative evaluation of methylprednisolone and dexamethasone injection into the masseter muscle in surgical removal of impacted lower third molars. Int J Curr Res Rev. 2012;4(19):133-6.

57. Darwade DA, Kumar S, Mehta R, Sharma AR, Reddy GS. In search of a better option: dexamethasone versus methylprednisolone in third molar impaction surgery. J Int Oral Health. 2014;6(6): 14-7.

58. Zerener T, Aydintug YS, Sencimen M, Bayar GR, Yazici M, Altug HA, Misir AF, Acikel C. Clinical comparison of submucosal injection of dexamethasone and triamcinolone acetonide on post-operative discomfort after third molar surgery. Quintessence Int. 2015;46:317-26.

59. Bahn SL. Glucocorticosteroids in dentistry. J Am Dent Assoc. 1982;105:476-81.

60. Thorn GW, Jenkins D, Laidlaw JC, Goetz FC, Dingman JF, Arons WL, Streeten DH, McCracken $\mathrm{BH}$. Medical progress; pharmacologic aspects of adrenocortical steroids and ACTH in man. N Engl J Med. 1953;248(8):323-37. 
61. Gersema L, Baker K. Use of corticosteroids in oral surgery. J Oral Maxillofac Surg. 1992;50:270-7.

62. Moraschini V, Hidalgo R. Effect of submucosal injection of dexamethasone after third molar surgery: a meta-analysis of randomized controlled trials. Int J Oral Maxillofac Surg. 2016;45(2):232-40.

63. Holte $\mathrm{K}$, Kehlet $\mathrm{H}$. Perioperative single dose glucocorticoid administration: pathophysiologic effects and clinical implications. J Am Coll Surg. 2002;195:694-712.

64. Valeriani M, Restuccia D, Di Lazzaro V, Oliverio A, Profice P, Le Pera D, Saturno E, Tonali P. Inhibition of human primary motor area by painful heat stimulation of the skin. Clin Neurophysiol. 1999;110:1475-80.

65. Romaniello A, Cruccu G, Mcmillan AS, Arendt-Nielsen L, Svensson P. Effect of experimental pain from trigeminal muscle and skin on motor cortex excitability in humans. Brain Res. 2000;882:120-7.

66. Beirne OR, Hollander B. The effect of methylprednisolone on pain, trismus, and swelling after removal of third molars. OralSurg Oral Med Oral Pathol. 1986;61:134-8.

67. Milles M, Desjardins PJ. Reduction of post-operative facial swelling by low-dose methylprednisolone. J Oral Maxillofac Surg. 1993;51:987-91.

68. Hargreaves KM, Shmidt EA, Mueller GP, Dionne RA. Dexamethasone alters plasma levels of beta-endorphin and post-operative pain. Clin Pharmacol Ther. 1987;42:601-7.

69. Moore PA, Brar P, Smiga ER, Costello BJ. Preemptive rofecoxib and dexamethasone for prevention of pain and trismus following third molar surgery. Oral Surg Oral Med Oral Pathol Oral Radiol Endod. 2005;99:E1-7.
70. Buyukkurt MC, Gungormus M, Kaya O. The effect of a single dose prednisolone with and without diclophenac on pain trismus and swelling after removal of mandibular third molars. J Oral Maxillofac Surg. 2006;12:1761-6.

71. Lin TC, Lui MT, Chang RC. Premedication with diclophenac and prednisolone to prevent post-operative pain and swelling after third molar removal. Zhonghua Yi Xue Za Zhi (Taipei). 1996;58:40-4.

72. Ahlgren SC, Wang JF, Levine JD. C-fiber mechanical stimulus-response functions are different in inflammatory versus neuropathic hyperalgesia in the rat. Neuroscience. 1996;76(1):285-90.

73. Esen E, Tasar F, Akhan O. Determination of the anti-inflammatory effects of methylprednisolone on the sequelae of third molar surgery. J Oral Maxillofac Surg. 1999;10:1201-6.

74. Jarrah MH, Al-Rabadi HF, Imrayan M, Al-share' AA. Single dose of dexamethasone with or without ibuprofen effects on post-operative sequelae of lower third molar surgical extraction. J R Med Serv. $2015 ; 22(1): 41-45$.

75. Mirzai H, Tekin I, Alincak H. Perioperative use of corticosteroid and bupivacaine combination in lumbar disc surgery: a randomized controlled trial. Spine. 2002;27(4):343-6.

76. Valergakis FE, Critides S, Winokur GL. Gastrointestinal complications in neuro-surgical patients treated with steroids. Am J Gastroenterol. 1972;58:441-6.

77. Bunim JJ. Clinical uses and hazards of adrenal steroids and their analogues in the management of rheumatic diseases. Bull N Y Acad Med. 1957;33(7):461-73. 